Supporting info for:

\title{
Polyglyoxylamides with a pH-Mediated Solubility and Depolymerization
}

\section{Switch}

Quinton E. A. Sirianni, ${ }^{\dagger \gamma}$ Xiaoli Liang, ${ }^{\dagger \gamma}$ Georgina K. Such, ${ }^{\#}$ and Elizabeth R. Gillies ${ }^{\dagger \gamma{ }^{* *}}$

'Department of Chemistry, The University of Western Ontario, London, Ontario, Canada, N6A $5 \mathrm{~B} 7$.

${ }^{\gamma}$ The Centre for Advanced Materials and Biomaterials Research, The University of Western Ontario, London, Ontario, Canada, N6A 5B7.

${ }^{\#}$ The School of Chemistry, The University of Melbourne, Parkville, Victoria, Australia, 3010.

Department of Chemical and Biochemical Engineering, The University of Western Ontario, London, Ontario, Canada, N6A 5B9.

\section{Table of Contents}

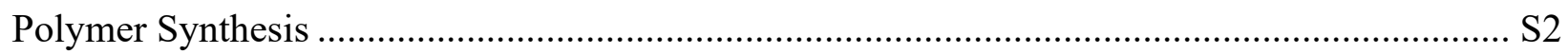

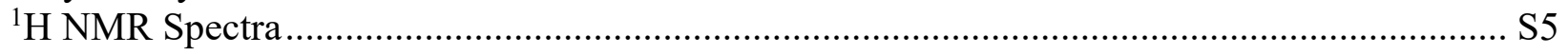

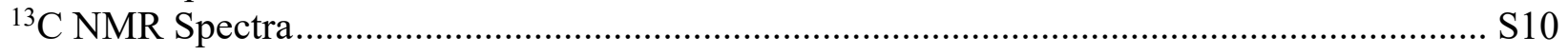

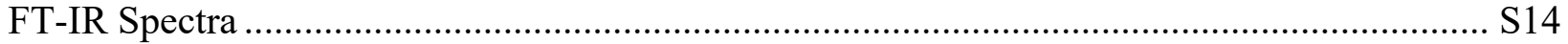

Size-Exclusion Chromatograms …………………...................................................... S15

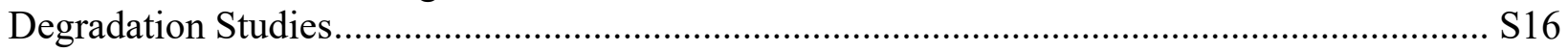

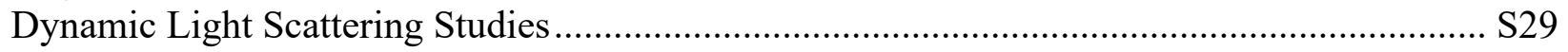

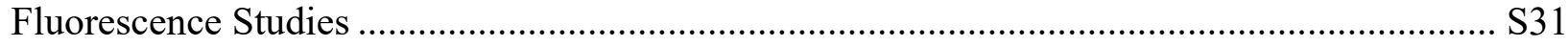

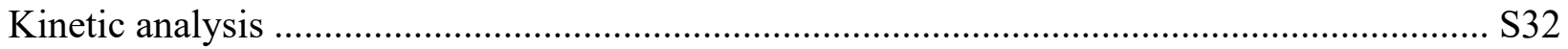

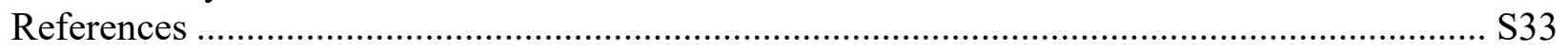




\section{Polymer Synthesis}

Synthesis of PEtG-1. AgOTf (0.44 g, $1.7 \mathrm{mmol}, 2.8$ equiv) and 4-propargyloxytrityl chloride $(0.57 \mathrm{~g}, 1.7,2.8$ equiv) were added to a flask, which was subsequently evacuated and purged with nitrogen. A $10 \mathrm{~mL}$ aliquot of dry $\mathrm{CH}_{2} \mathrm{Cl}_{2}$ was then added and the flask was stirred at room temperature for $1 \mathrm{~h}$ to yield the end-capping mixture. Separately, $60 \mathrm{~mL}$ of dry toluene were added to a flame-dried Schlenk flask under a nitrogen atmosphere along with $n$-butyl lithium $(0.24 \mathrm{~mL}$, 0.60 mmol, 1.0 equiv) Freshly distilled ethyl glyoxylate ${ }^{1}(13 \mathrm{~mL}, 130 \mathrm{mmol}, 220$ equiv) was subsequently added to the flask and the system was stirred and cooled at $-20^{\circ} \mathrm{C}$. After $30 \mathrm{~min}$, dry $\mathrm{NEt}_{3}(0.50 \mathrm{~mL}, 3.6 \mathrm{mmol}, 6.0$ equiv) was added to the polymerization flask and the mixture was allowed to stir for another $30 \mathrm{~min}$. The end-capping mixture was then cooled to $-20{ }^{\circ} \mathrm{C}$ before being transferred with a wide mouth pipette to the polymerization flask. The polymerization flask was stoppered and stirred at $-20^{\circ} \mathrm{C}$ for $4.5 \mathrm{~h}$ before being allowed to warm up to room temperature over $16 \mathrm{~h}$. Concentration of the crude polymerization mixture under vacuum followed by filtration and precipitation in $550 \mathrm{~mL}$ of $\mathrm{MeOH}: \mathrm{H}_{2} \mathrm{O}(10: 1)$ afforded $8.1 \mathrm{~g}$ of pure polymer residue as a clear pale orange tacky solid. Yield $=60 \% .{ }^{1} \mathrm{H}$ NMR $\left(\mathrm{CDCl}_{3}, 400 \mathrm{MHz}\right): \delta 7.32-7.50(\mathrm{~m}, 10 \mathrm{H}), 7.12-$ 7.32 (m, 45H), 6.85-6.93 (m, 3H), 5.46-5.74 (m, 198H), 4.67 (br s, 3H), 4.21 (br s, 413H), 2.54

(br s, 2H), 1.29 (br s, 617H), 0.88 (br s, 3H). ${ }^{13} \mathrm{C}\left\{{ }^{1} \mathrm{H}\right\} \mathrm{NMR}\left(\mathrm{CDCl}_{3}, 100 \mathrm{MHz}\right): \delta 165.1-166.5$, 127.2-129.3, 90.7-94.3, 62.2, 14.0. FT-IR (ATR): 2990, $1750 \mathrm{~cm}^{-1}$. SEC (DMF, PMMA): $M_{n}=$ $16 \mathrm{~kg} / \mathrm{mol}, M_{w}=29 \mathrm{~kg} / \mathrm{mol}, \oslash=1.7$.

Synthesis of PGAm(DEAE). PGAm(DEAE) was synthesized using the same procedure as PGAm(DMAE) except $N, N$-diethylethylenediamine (1.2 $\mathrm{mL}, 8.5 \mathrm{mmol}, 2.9$ equiv) was used and the crude mixture was dialyzed in a $10 \mathrm{~kg} / \mathrm{mol}$ molecular weight cut off (MWCO) regenerated 
cellulose membrane against acetone to afford $0.34 \mathrm{~g}$ of a clear, colourless, tacky solid. Yield $=$ 67\%. ${ }^{1} \mathrm{H}$ NMR $\left(\mathrm{CDCl}_{3}, 400 \mathrm{MHz}\right): \delta 7.56-8.90(\mathrm{~m}, 178 \mathrm{H}), 7.30-7.56(\mathrm{~m}, 9 \mathrm{H}), 7.16-7.30(\mathrm{~m}$, 14H), 6.86 (br s, 3H), 5.71 (br s, 177H), 4.65 (br s, 2H), 3.26 (br s, 350H), 2.50 (br s, 1037H), 0.97 (br s, 1027H). ${ }^{13} \mathrm{C}\left\{{ }^{1} \mathrm{H}\right\}$ NMR $\left(\mathrm{CDCl}_{3}, 100 \mathrm{MHz}\right): \delta 167.1,99.1,94.7,51.6,47.3,37.7,12.1$. FTIR (ATR): 3270, 3080, 2970, 2930, 2880, 2810, 1670, $1540 \mathrm{~cm}^{-1}$. SEC (DMF, PMMA): $M_{n}=11$ $\mathrm{kg} / \mathrm{mol}, M_{w}=23 \mathrm{~kg} / \mathrm{mol}, \oslash=2.1$.

Synthesis of PGAm(DPAE). PGAm(DPAE) was synthesized using the same procedure as PGAm(DMAE) except $N, N$-diisopropylethylenediamine $(1.5 \mathrm{~mL}, 8.6 \mathrm{mmol}, 3.0$ equiv) was used and the crude mixture was precipitated in $50 \mathrm{~mL}$ of $\mathrm{MeOH}$ to afford $0.35 \mathrm{~g}$ of a clear, colourless, brittle solid. Yield $=59 \% .{ }^{1} \mathrm{H}$ NMR $\left(\mathrm{CDCl}_{3}, 400 \mathrm{MHz}\right): \delta 7.52-9.07(\mathrm{~m}, 214 \mathrm{H}), 7.33-7.52(\mathrm{~m}$, 8H), 7.15-7.33 (m, 17H), 6.87 (s, 2H), $5.73(\mathrm{~s}, 203 \mathrm{H}), 4.65(\mathrm{~s}, 2 \mathrm{H}), 3.16(\mathrm{~s}, 388 \mathrm{H}), 2.94(\mathrm{~s}, 416 \mathrm{H})$, $2.51(\mathrm{~s}, 432 \mathrm{H}), 0.97(\mathrm{~s}, 2447 \mathrm{H}) .{ }^{13} \mathrm{C}\left\{{ }^{1} \mathrm{H}\right\} \mathrm{NMR}\left(\mathrm{CDCl}_{3}, 100 \mathrm{MHz}\right): \delta$ 167.0, 93.9-100.2, 48.8, 44.0, 40.8, 21.0. FT-IR (ATR): 3280, 3080, 2960, 2870, 2820, 1670, $1540 \mathrm{~cm}^{-1}$.

Synthesis of PEtG-2. PEtG-2 was synthesized using the same procedure at PEtG-1 except the following equivalents were used: purified ethyl glyoxylate ( $15 \mathrm{~mL}, 150 \mathrm{mmol}, 100$ equiv), $n$-butyl lithium (0.61 mL, $1.5 \mathrm{mmol}, 1.0$ equiv), $\mathrm{NEt}_{3}(0.84 \mathrm{~mL}, 6.0 \mathrm{mmol}, 4.0$ equiv), $\operatorname{AgOTf}(0.85 \mathrm{~g}, 3.3$ mmol, 2.2 equiv), 4-propargyloxytrityl chloride ( $1.1 \mathrm{~g}, 3.3 \mathrm{mmol}, 2.2$ equiv). After addition of the end-cap mixture, the reaction was stirred for $4 \mathrm{~h}$ before being allowed to warm up over $16 \mathrm{~h}$. Purification was achieved by concentration of the reaction mixture followed by filtration and precipitation into $750 \mathrm{~mL}$ of $\mathrm{MeOH}: \mathrm{H}_{2} \mathrm{O}$ (4:1). The resulting precipitate was dissolved in $\mathrm{CH}_{2} \mathrm{Cl}_{2}$ and mixed with activated carbon before being further filtered through Celite to afford $5.9 \mathrm{~g}$ of a yellow-orange tacky solid. Yield $=38 \% .{ }^{1} \mathrm{H} \mathrm{NMR}\left(\mathrm{CDCl}_{3}, 400 \mathrm{MHz}\right): \delta 7.33-7.49(\mathrm{~m}, 8 \mathrm{H}), 7.17-$ $7.33(\mathrm{~m}, 21 \mathrm{H}), 6.86-6.93(\mathrm{~m}, 2 \mathrm{H}), 5.40-5.82(\mathrm{~m}, 100 \mathrm{H}), 4.67$ (br s, 2H), 4.22 (br s, 197H), 2.55 
(br s, 1H), 1.29 (br s, 296H), 0.88 (br s, 3H). ${ }^{13} \mathrm{C}\left\{{ }^{1} \mathrm{H}\right\}$ NMR (CDCl, $\left.100 \mathrm{MHz}\right): \delta 165.2-166.5$, 18.7, 128.0, 127.5, 90.6-94.4, 62.2, 14.0. FT-IR (ATR): 2960, $1750 \mathrm{~cm}^{-1}$. SEC (DMF, PMMA): $M_{n}=11 \mathrm{~kg} / \mathrm{mol}, M_{w}=17 \mathrm{~kg} / \mathrm{mol}, \oslash=1.5$.

Synthesis of PEG-PEtG. PEtG-2 (1.5 g, 0.15 mmol, 1.0 equiv), mPEG-N $_{\mathbf{3}}(1.2 \mathrm{~g}, 0.60 \mathrm{mmol}$, 4.0 equiv), $\mathrm{CuSO}_{4}(0.018 \mathrm{~g}, 0.11 \mathrm{mmol}, 0.73$ equiv), and sodium $\mathrm{L}$-ascorbate $(0.023 \mathrm{~g}, 0.12 \mathrm{mmol}$, 0.80 equiv) were dissolved in $15 \mathrm{~mL}$ of glass-distilled DMF. After purging the solution for $1 \mathrm{~h}$ by bubbling through nitrogen gas, the reaction mixture was heated to $40{ }^{\circ} \mathrm{C}$ and stirred under nitrogen for $20 \mathrm{~h}$. The crude reaction mixture was dialyzed in a $10 \mathrm{~kg} / \mathrm{mol}$ MWCO regenerated cellulose membrane against water for $16 \mathrm{~h}$ until the mixture turned turbid. The mixture was then centrifuged, and the supernatant was discarded. The pellet that remained was resuspended in $30 \mathrm{~mL}$ of water,

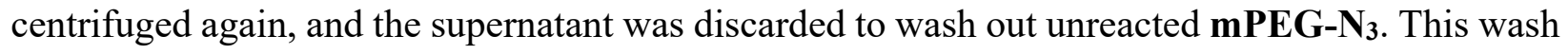
procedure was repeated three-fold before the pellet was resuspended, flash frozen, and lyophilized to afford $1.3 \mathrm{~g}$ of a white spongy solid. Yield $=72 \% .{ }^{1} \mathrm{H}$ NMR $\left(\mathrm{CDCl}_{3}, 400 \mathrm{MHz}\right): \delta 7.40-7.48$ (m, 4H), 7.18-7.38 (m, 14H), 6.87-6.98 (m, 2H), 5.40-5.76 (m, 103H), 4.60 (br s, 2H), 4.22 (br s, $210 \mathrm{H}), 3.64$ (br s, $178 \mathrm{H}), 3.37$ (s, 3H), 1.28 (br s, $327 \mathrm{H}), 0.87$ (br s, $3 \mathrm{H}) .{ }^{13} \mathrm{C}\left\{{ }^{1} \mathrm{H}\right\} \mathrm{NMR}\left(\mathrm{CDCl}_{3}\right.$, $100 \mathrm{MHz}): \delta$ 164.9-166.7, 90.3-94.3, 70.7, 62.2, 14.0. FT-IR (ATR): 2980, 2940, 2880, 1750 $\mathrm{cm}^{-1}$. SEC (DMF, PMMA): $M_{n}=14 \mathrm{~kg} / \mathrm{mol}, M_{w}=20 \mathrm{~kg} / \mathrm{mol}, \nexists=1.4$.

Synthesis of PEG-PGAm(DEAE). PEG-PGAm(DEAE) was synthesized following the same procedure as PEG-PGAm(DMAE) except $N, N$-diethylethylenediamine (1.3 mL, $9.3 \mathrm{mmol}, 3.3$ equiv) was used to afford $0.31 \mathrm{~g}$ of an off-yellow tacky solid. Yield $=56 \%$. ${ }^{1} \mathrm{H} \mathrm{NMR}\left(\mathrm{CDCl}_{3}, 400\right.$ MHz): $\delta 7.78-8.77(\mathrm{~m}, 133 \mathrm{H}), 7.36-7.50(\mathrm{~m}, 10 \mathrm{H}), 7.18-7.36(\mathrm{~m}, 56 \mathrm{H}), 6.86-6.93(\mathrm{~m}, 4 \mathrm{H}), 5.74$ (br s, 104H), 4.54 (br s 4H), 3.64 (br s, 178H), 3.29 (br s, 232H), 2.55 (br s, 750H), 1.01 (br s, 712H). ${ }^{13} \mathrm{C}\left\{{ }^{1} \mathrm{H}\right\}$ NMR $\left(\mathrm{CDCl}_{3}, 100 \mathrm{MHz}\right): \delta 167.1,94.2-99.5,70.7,51.6,47.3,37.7,12.1 . \mathrm{FT}-\mathrm{IR}$ 
(ATR): 3280, 3080, 2970, 2930, 2870, 2810, $1670 \mathrm{~cm}^{-1}$. SEC (DMF, PMMA): $M_{n}=19 \mathrm{~kg} / \mathrm{mol}$, $M_{w}=25 \mathrm{~kg} / \mathrm{mol}, \oslash=1.3$.

Synthesis of PEG-PGAm(DPAE). PEG-PGAm(DPAE) was synthesized following the same procedure as PEG-PGAm(DMAE) except $N, N$-diisopropylethylenediamine $(1.6 \mathrm{~mL}, 9.2 \mathrm{mmol}$, 3.3 equiv) was used and the crude mixture was dialyzed against a 1:1 ethyl acetate:acetone solution to afford $0.40 \mathrm{~g}$ of a yellow brittle solid. Yield $=62 \% .{ }^{1} \mathrm{H}$ NMR $\left(\mathrm{CDCl}_{3}, 400 \mathrm{MHz}\right): \delta 7.72-8.78$ (m, 110H), 7.40-7.49 (m, 6H), 7.16-7.40 (m, 24H), 6.89 (br s, 2H), 5.72 (br s, 104H), 4.54 (br s, 2H), 3.64 (br s, 178H), 3.37 (s, 5H), 3.17 (br s, 239H), 2.96 (br s, 251H), 2.52 (br s, 243H), 0.98 (br s, $1530 \mathrm{H}) .{ }^{13} \mathrm{C}\left\{{ }^{1} \mathrm{H}\right\} \mathrm{NMR}\left(\mathrm{CDCl}_{3}, 100 \mathrm{MHz}\right): \delta 166.9,94.4-100.1,70.7,48.9,44.0,40.6,21.0$. FT-IR (ATR): 3280, 3080, 2960, 2870, 2820, 1670, $1540 \mathrm{~cm}^{-1}$. SEC (DMF, PMMA): $M_{n}=16$ $\mathrm{kg} / \mathrm{mol}, M_{w}=21 \mathrm{~kg} / \mathrm{mol}, \oslash=1.3$.

\section{${ }^{1}$ H NMR Spectra}

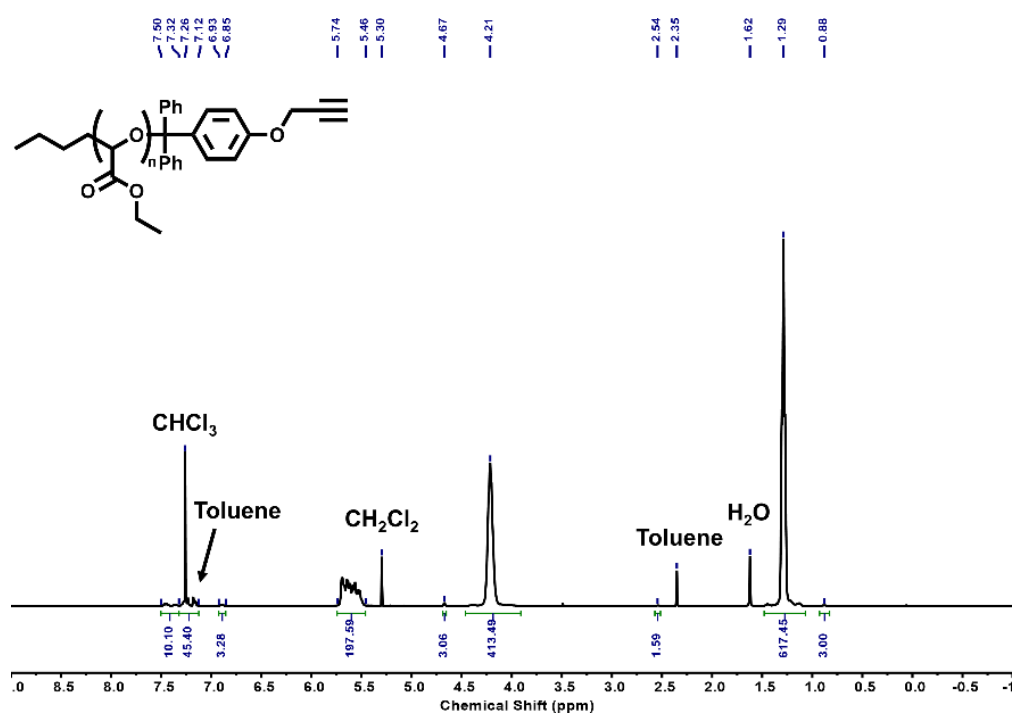

Figure S1. ${ }^{1} \mathrm{H}$ NMR spectrum of PEtG-1 $\left(\mathrm{CDCl}_{3} ; 400 \mathrm{MHz}\right)$. 


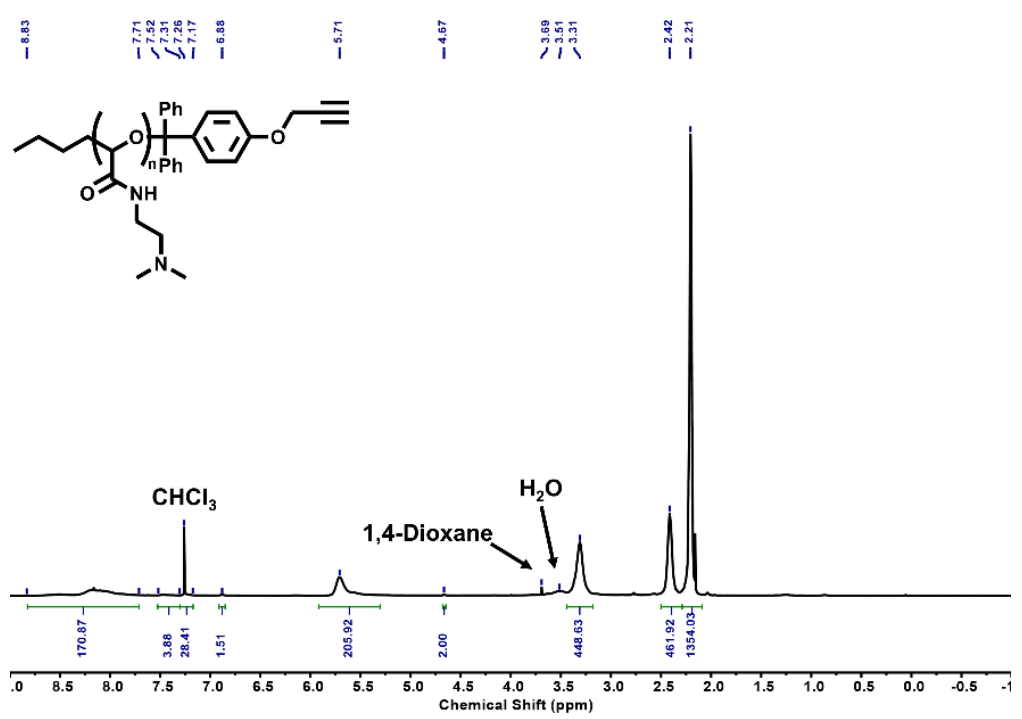

Figure S2. ${ }^{1} \mathrm{H}$ NMR spectrum of PGAm(DMAE) $\left(\mathrm{CDCl}_{3} ; 400 \mathrm{MHz}\right)$.

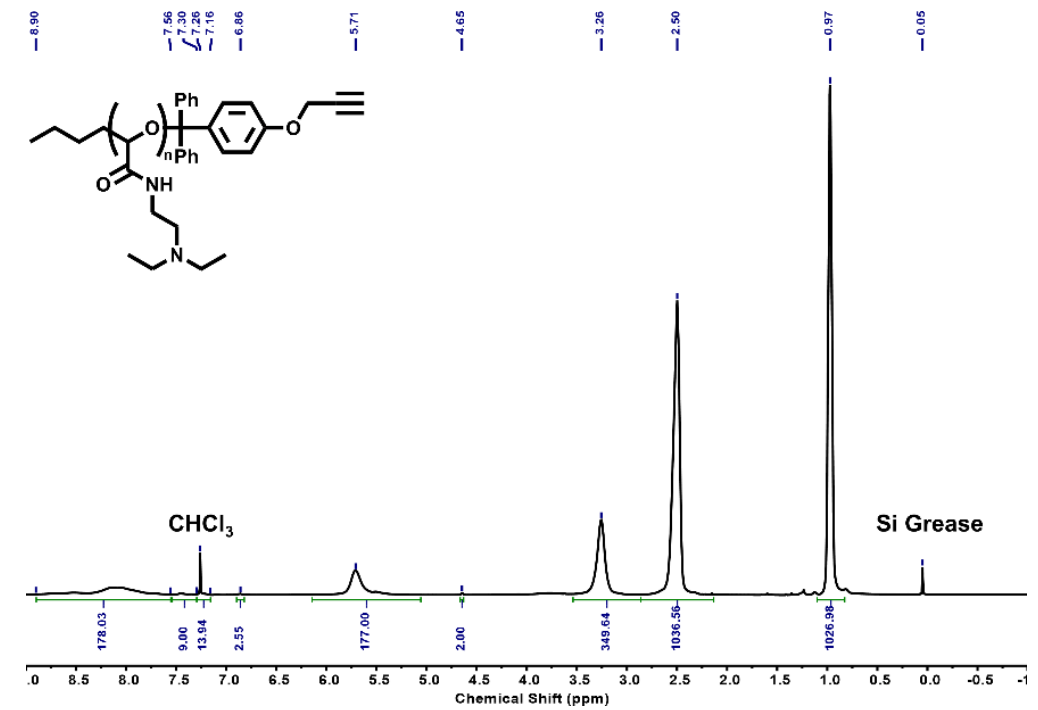

Figure S3. ${ }^{1} \mathrm{H}$ NMR spectrum of PGAm(DEAE) $\left(\mathrm{CDCl}_{3} ; 400 \mathrm{MHz}\right)$. 


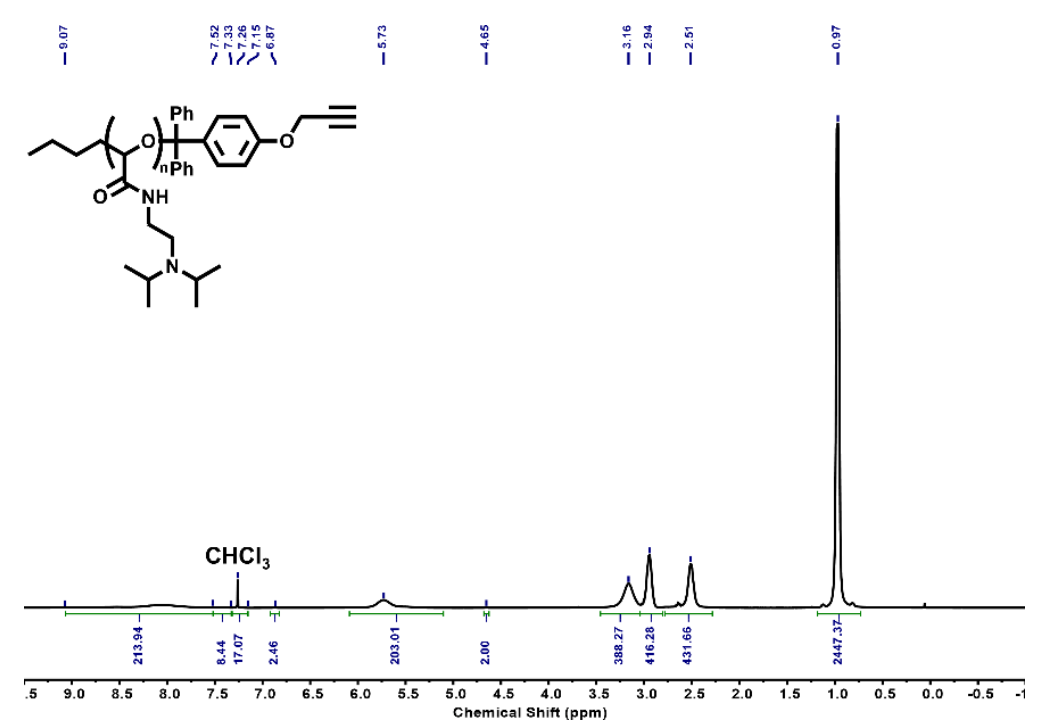

Figure S4. ${ }^{1} \mathrm{H}$ NMR spectrum of PGAm(DPAE) $\left(\mathrm{CDCl}_{3} ; 400 \mathrm{MHz}\right)$.
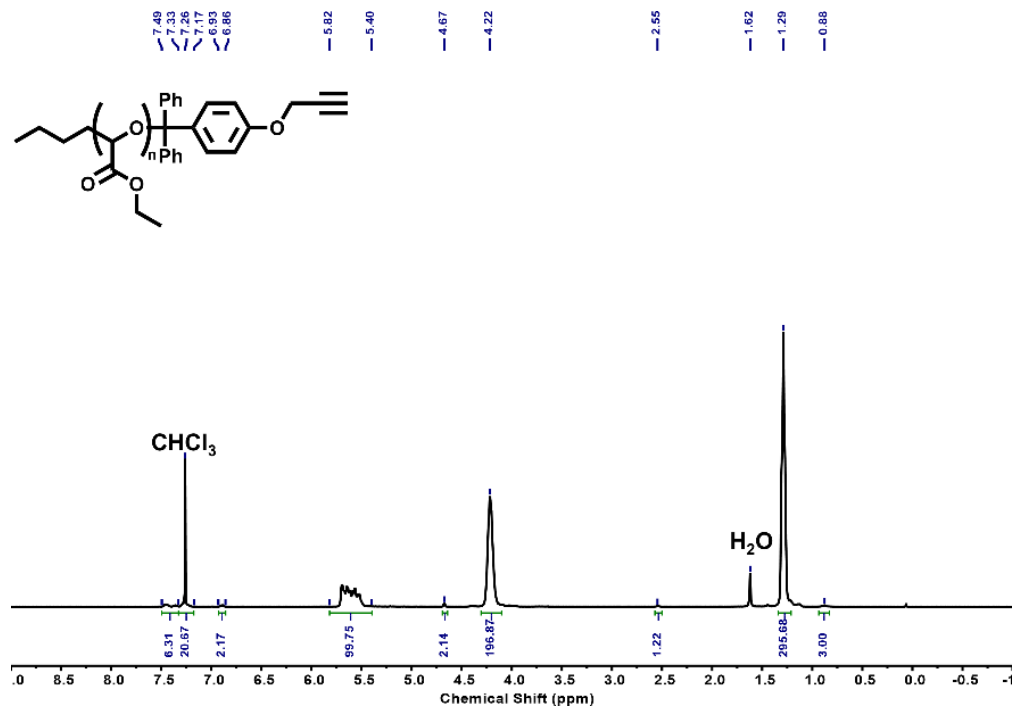

Figure S5. ${ }^{1} \mathrm{H}$ NMR spectrum of PEtG-2 $\left(\mathrm{CDCl}_{3} ; 400 \mathrm{MHz}\right)$. 


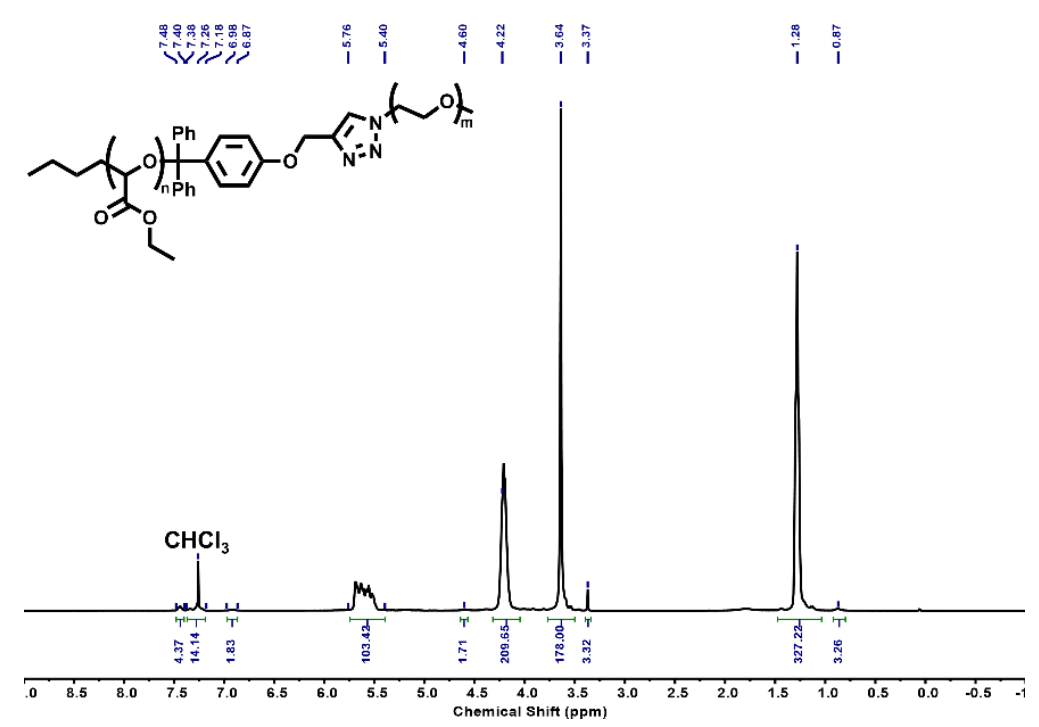

Figure S6. ${ }^{1} \mathrm{H}$ NMR spectrum of PEG-PEtG $\left(\mathrm{CDCl}_{3} ; 400 \mathrm{MHz}\right)$.

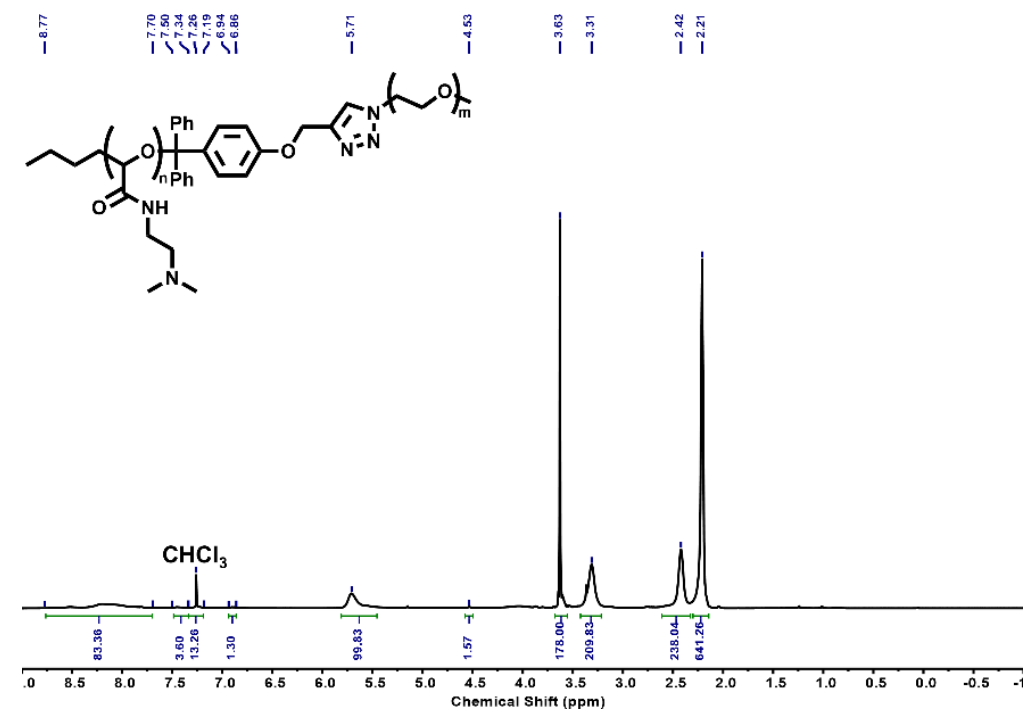

Figure S7. ${ }^{1} \mathrm{H}$ NMR spectrum of PEG-PGAm(DMAE) $\left(\mathrm{CDCl}_{3} ; 400 \mathrm{MHz}\right)$. 


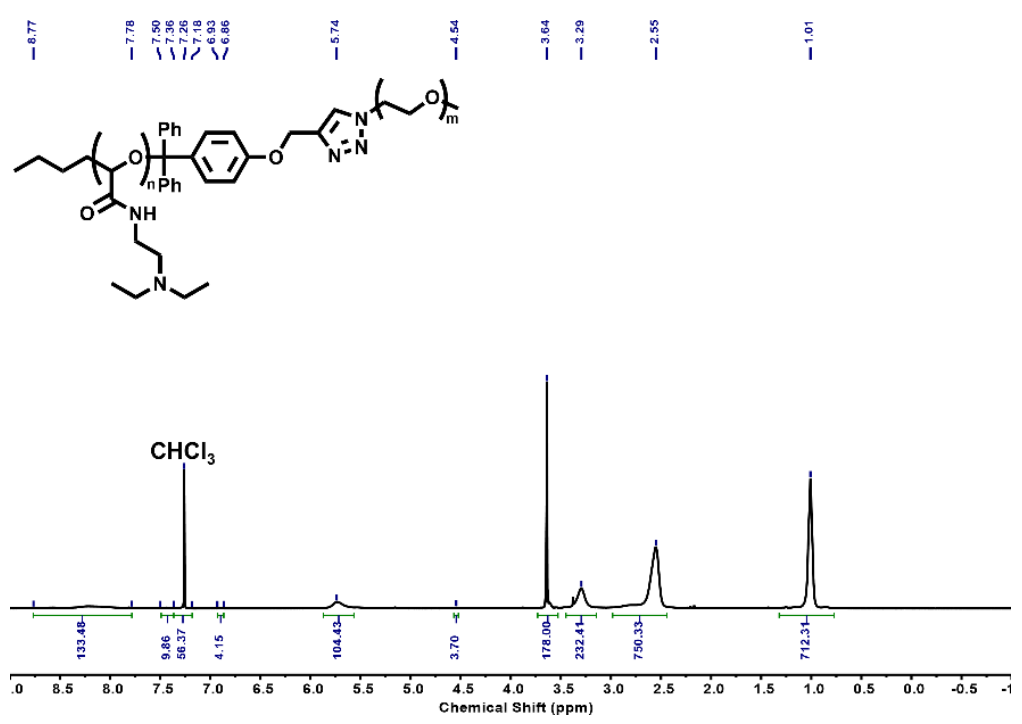

Figure S8. ${ }^{1} \mathrm{H}$ NMR spectrum of PEG-PGAm(DEAE) $\left(\mathrm{CDCl}_{3} ; 400 \mathrm{MHz}\right)$.

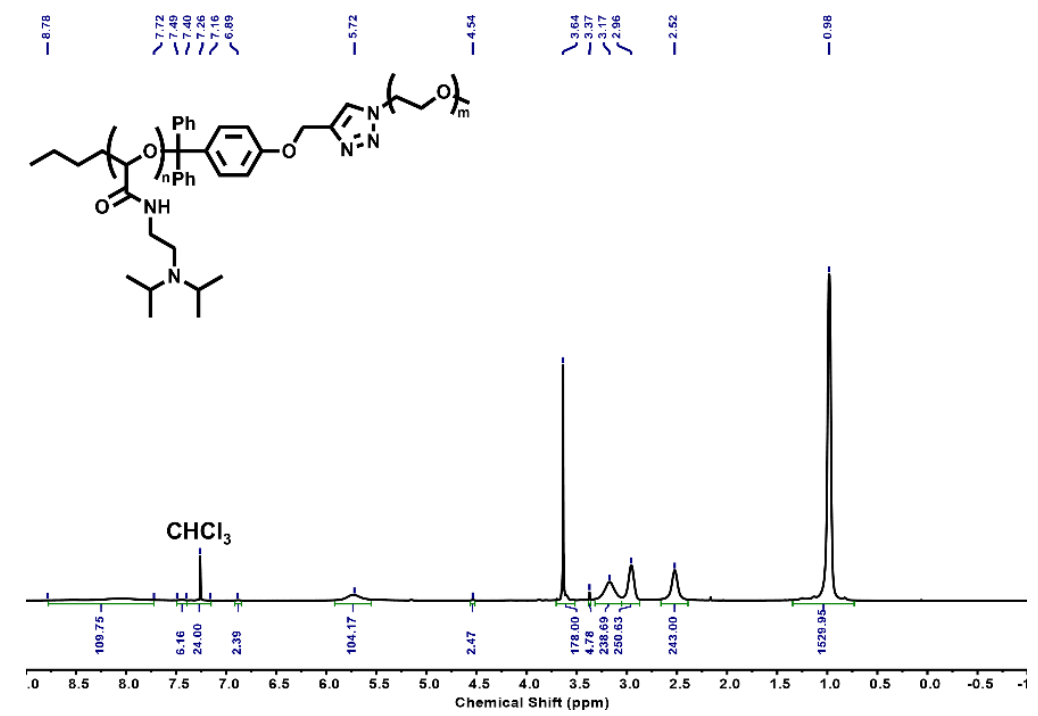

Figure S9. ${ }^{1} \mathrm{H}$ NMR spectrum of PEG-PGAm(DPAE) $\left(\mathrm{CDCl}_{3} ; 400 \mathrm{MHz}\right)$. 


\section{${ }^{13} \mathrm{C}$ NMR Spectra}
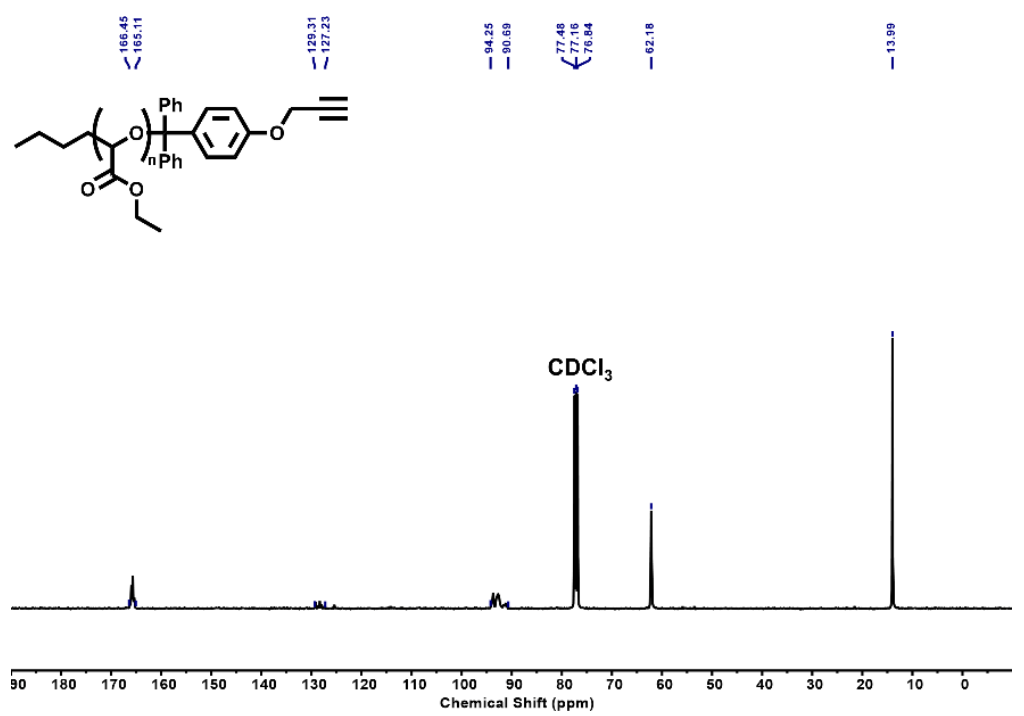

Figure S10. ${ }^{13} \mathrm{C}$ NMR spectrum of PEtG-1 $\left(\mathrm{CDCl}_{3} ; 100 \mathrm{MHz}\right)$.
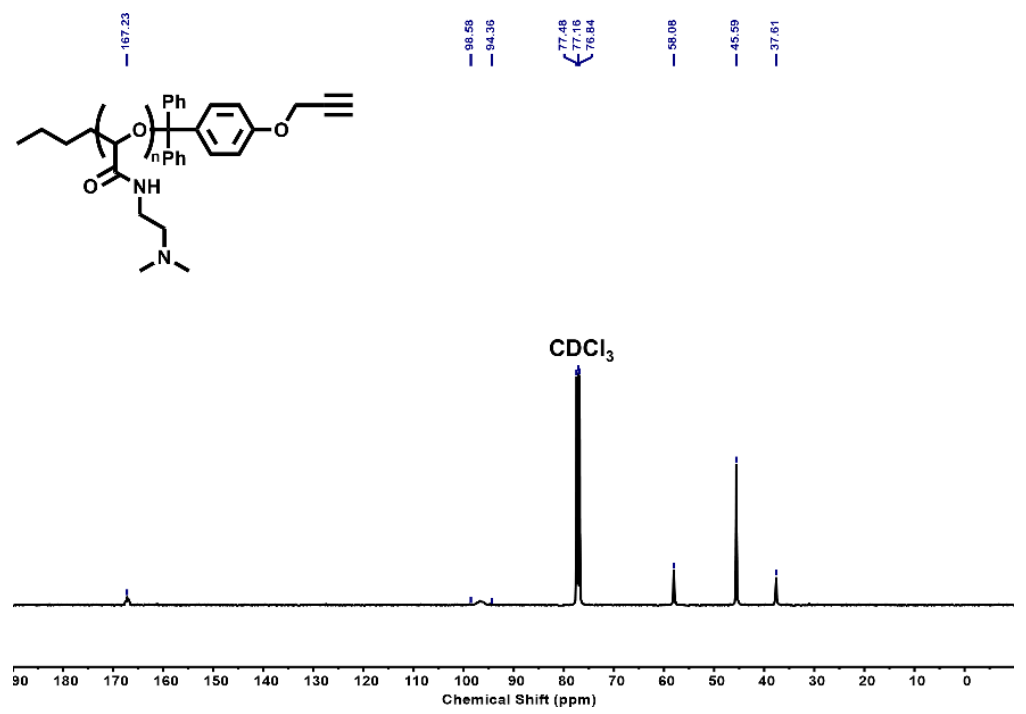

Figure S11. ${ }^{13} \mathrm{C}$ NMR spectrum of PGAm(DMAE) $\left(\mathrm{CDCl}_{3} ; 100 \mathrm{MHz}\right)$. 

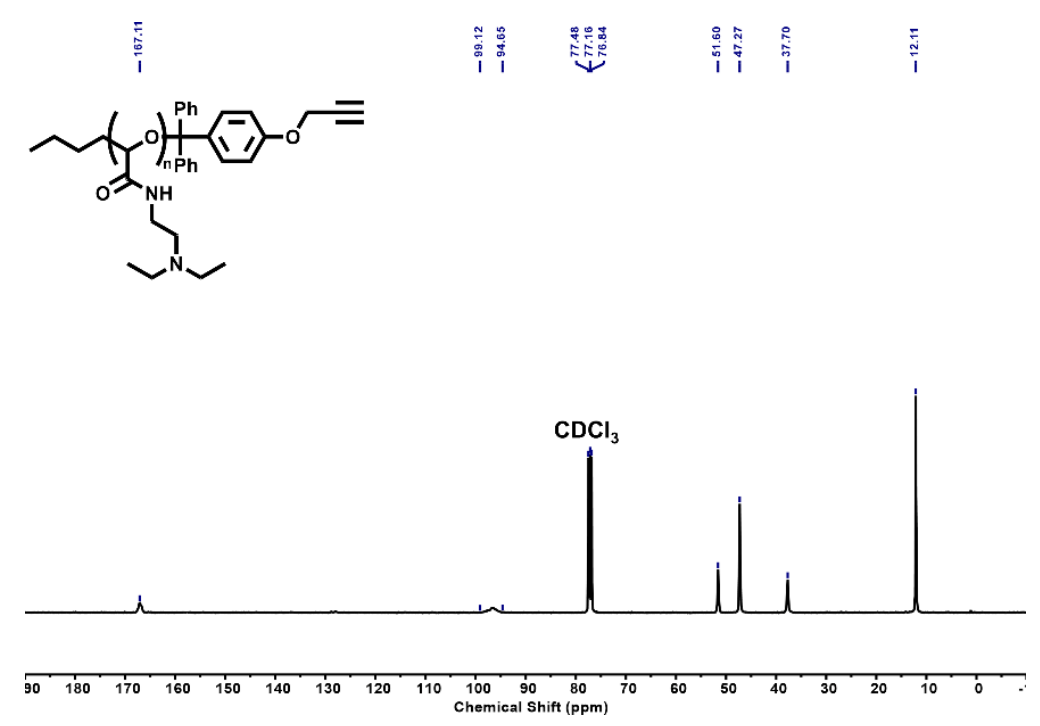

Figure S12. ${ }^{13} \mathrm{C}$ NMR spectrum of PGAm(DEAE) $\left(\mathrm{CDCl}_{3} ; 100 \mathrm{MHz}\right)$.

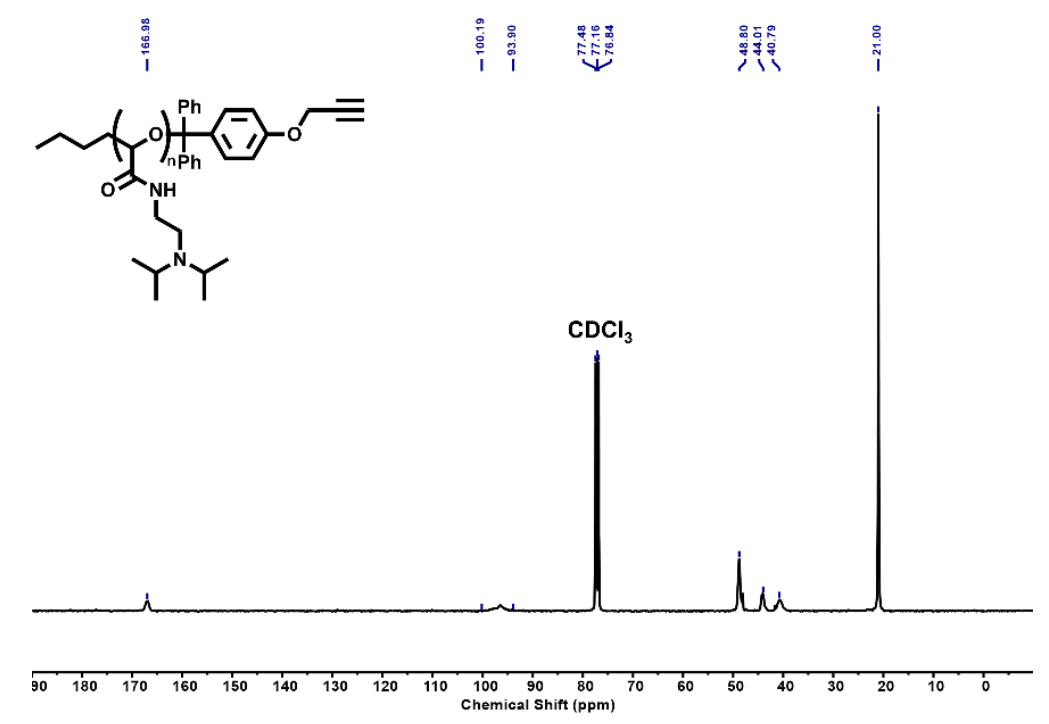

Figure S13. ${ }^{13} \mathrm{C}$ NMR spectrum of PGAm(DPAE) $\left(\mathrm{CDCl}_{3} ; 100 \mathrm{MHz}\right)$. 

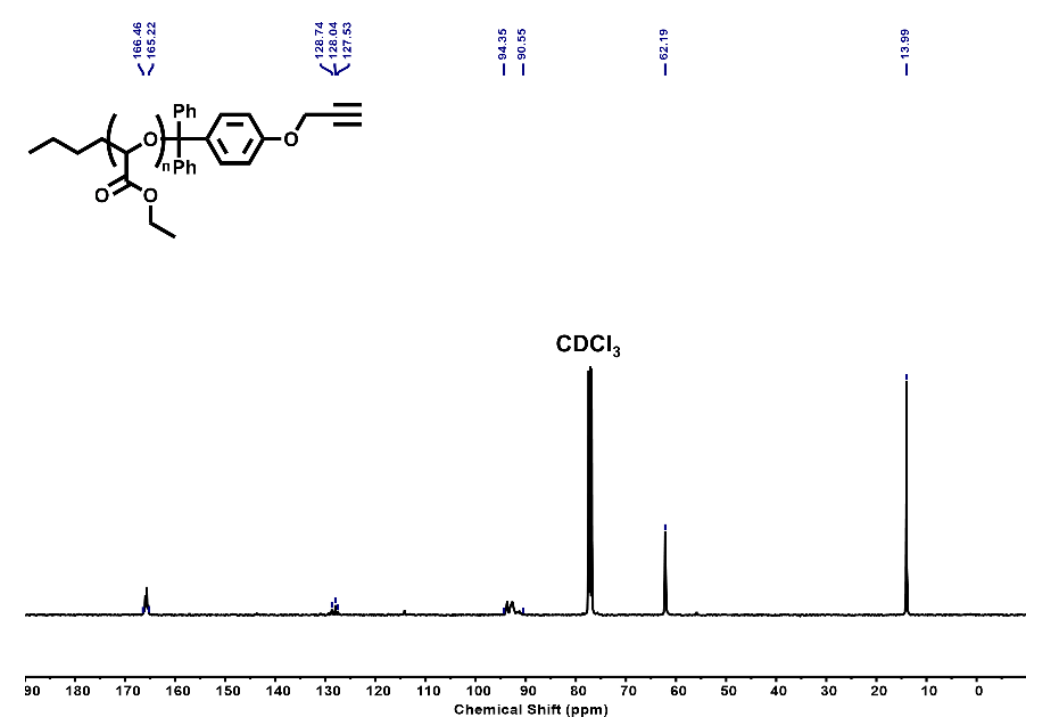

Figure S14. ${ }^{13} \mathrm{C}$ NMR spectrum of PEtG-2 $\left(\mathrm{CDCl}_{3} ; 100 \mathrm{MHz}\right)$.

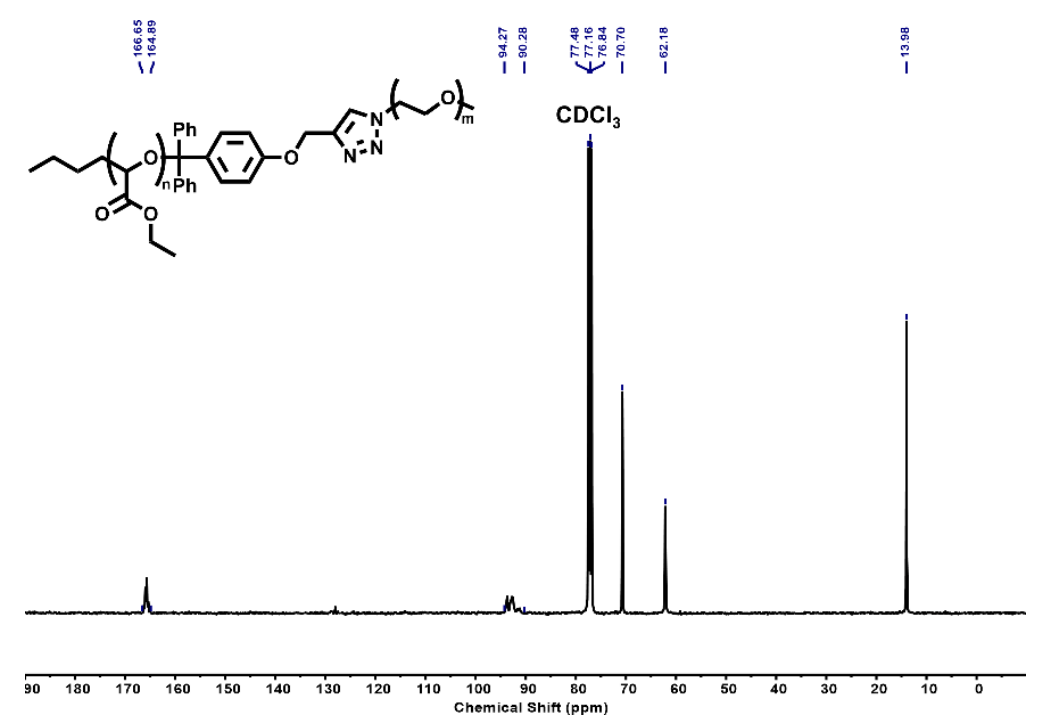

Figure S15. ${ }^{13} \mathrm{C}$ NMR spectrum of PEG-PEtG $\left(\mathrm{CDCl}_{3} ; 100 \mathrm{MHz}\right)$. 

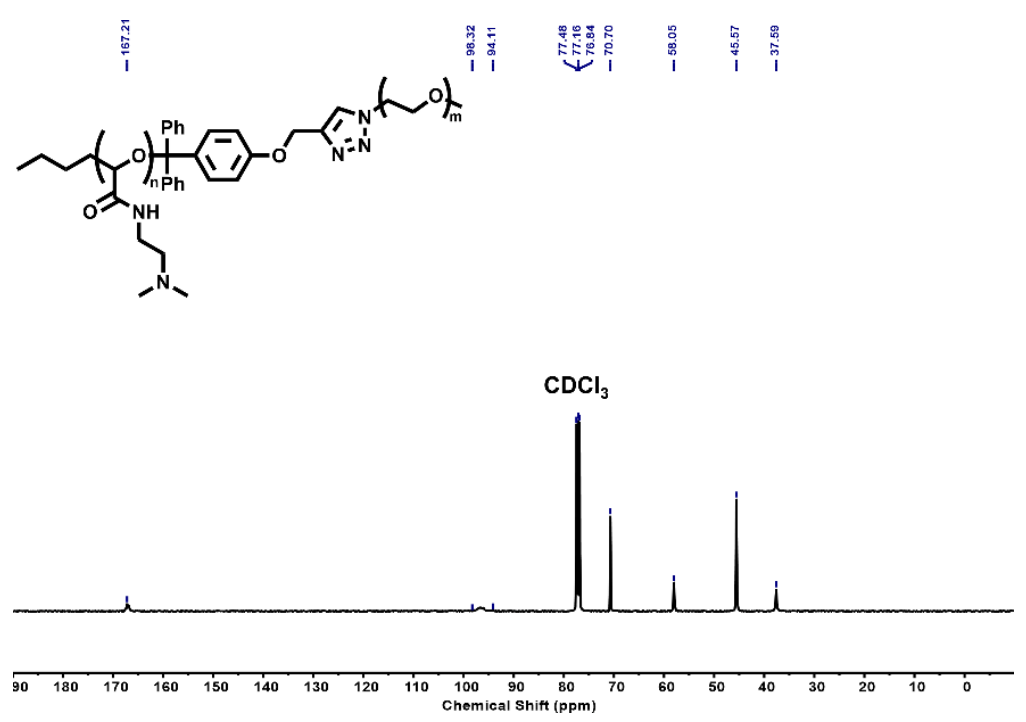

Figure S16. ${ }^{13} \mathrm{C}$ NMR spectrum of PEG-PGAm(DMAE) $\left(\mathrm{CDCl}_{3} ; 100 \mathrm{MHz}\right)$.

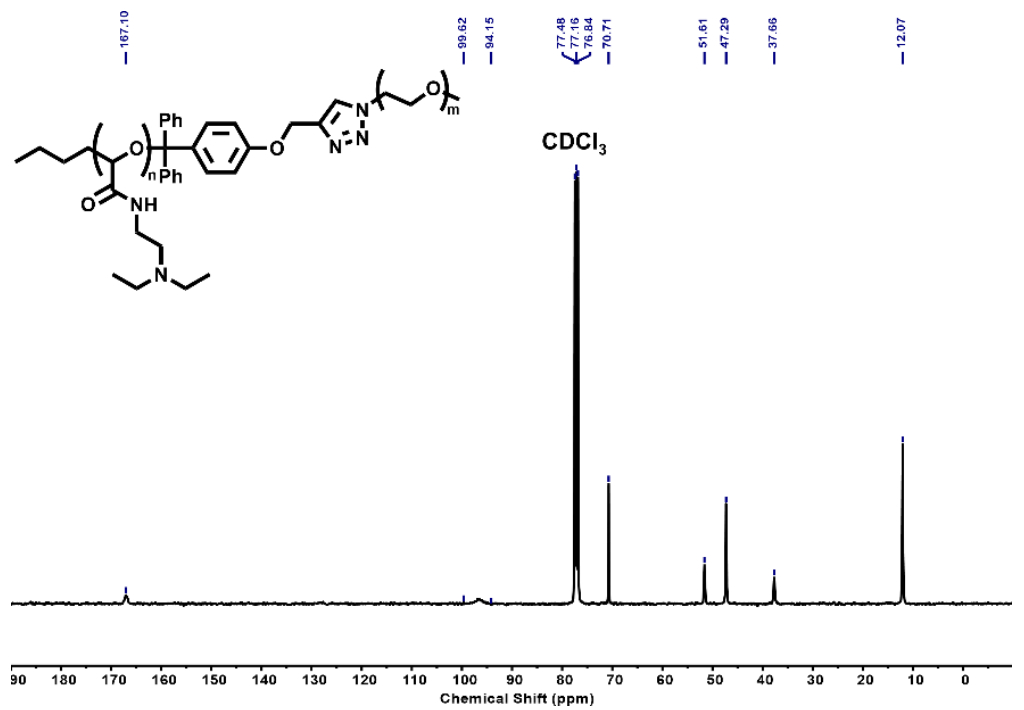

Figure S17. ${ }^{13} \mathrm{C}$ NMR spectrum of PEG-PGAm(DEAE) $\left(\mathrm{CDCl}_{3} ; 100 \mathrm{MHz}\right)$. 


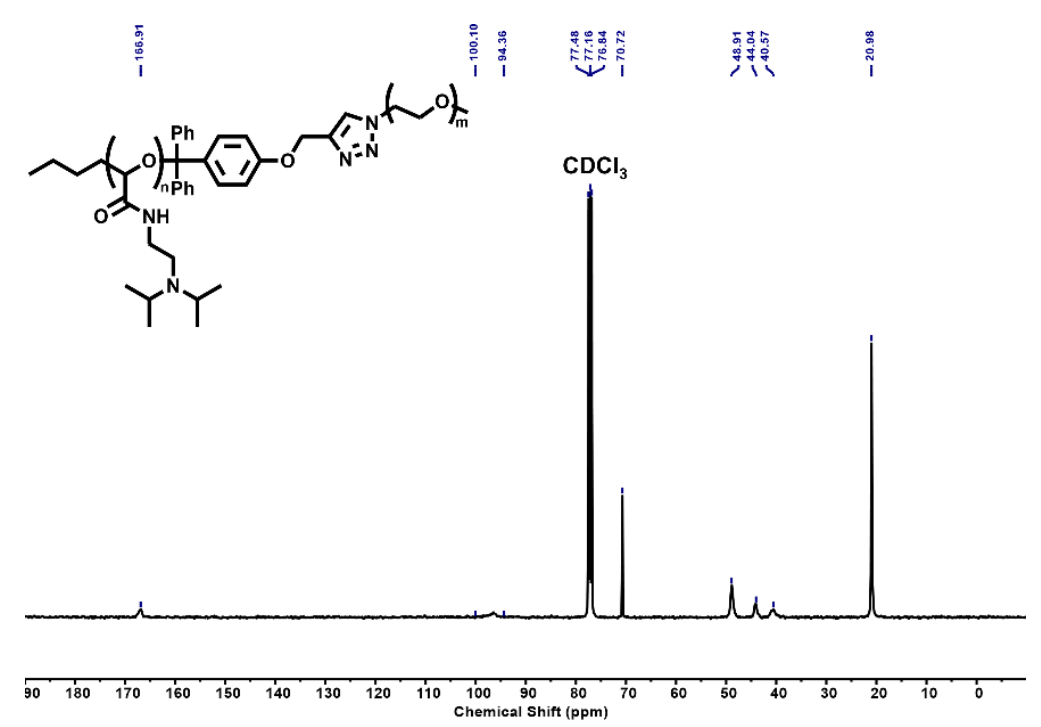

Figure S18. ${ }^{13} \mathrm{C}$ NMR spectrum of PEG-PGAm(DPAE) $\left(\mathrm{CDCl}_{3} ; 100 \mathrm{MHz}\right)$.

\section{FT-IR Spectra}

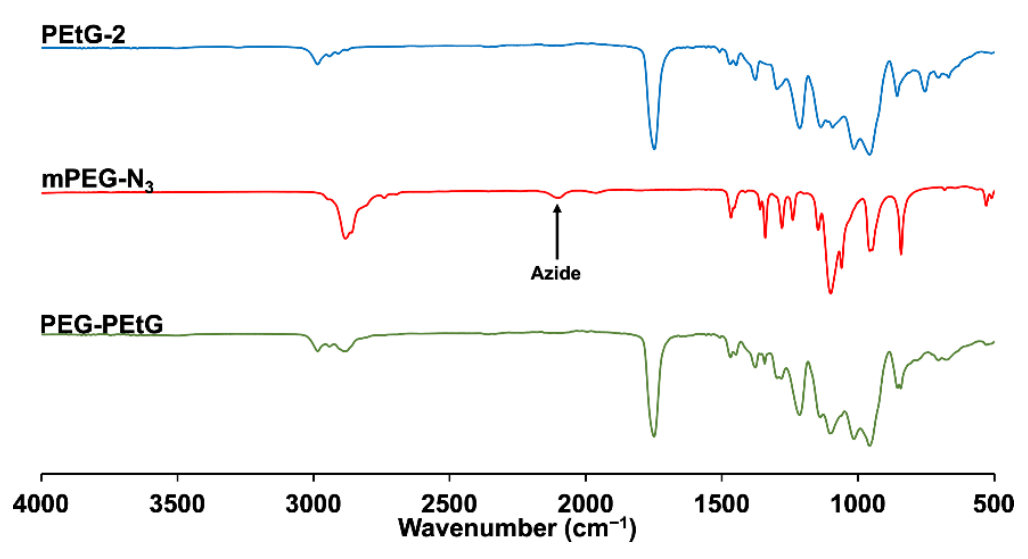

Figure S19. Overlay of FT-IR spectra of PEtG-2, mPEG-N 3 , and PEG-PEtG. The azide stretch peak at $\sim 2100 \mathrm{~cm}^{-1}$ disappears in the final copolymer, indicating that no free $\mathbf{~ m P E G - N _ { 3 }}$ impurity is present. 


\section{Size-Exclusion Chromatograms}

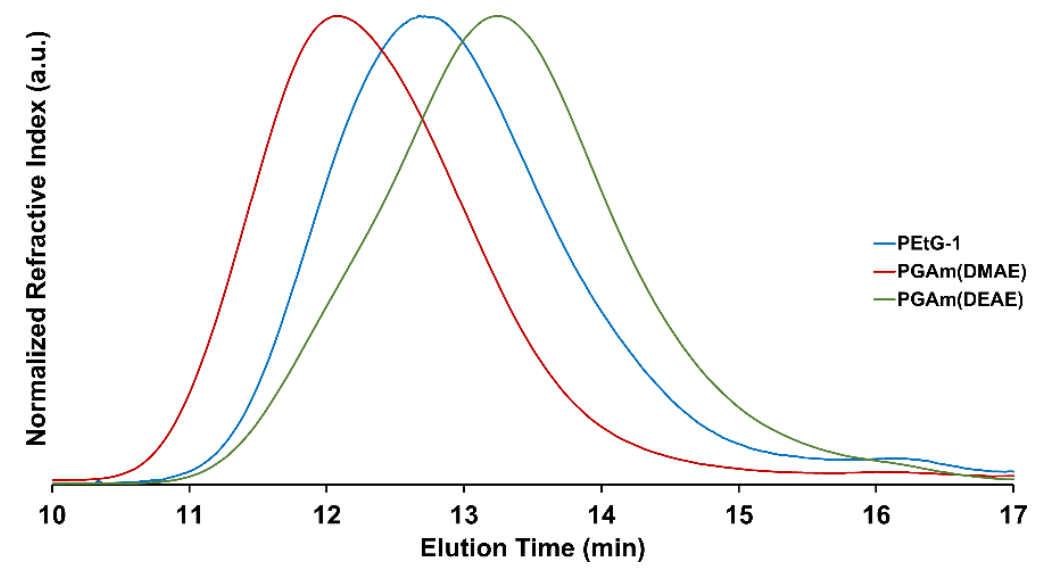

Figure S20. Overlay of chromatograms of the homopolymers PEtG-1, PGAm(DMAE), and PGAm(DEAE). PGAm(DPAE) was not soluble in the DMF eluent and thus could not be run on the column.

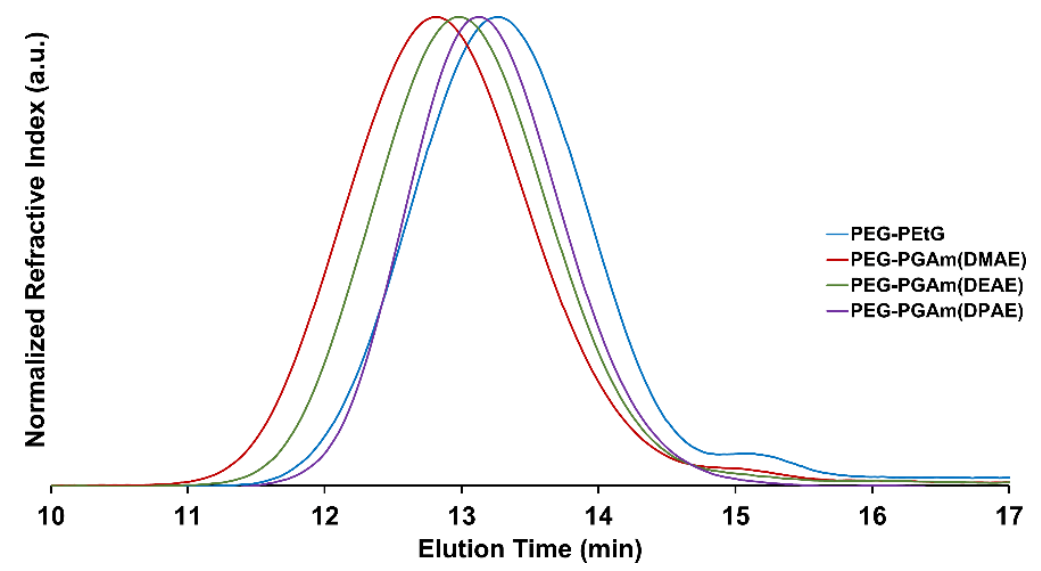

Figure S21. Overlay of the chromatograms of the block copolymers PEG-PEtG, PEGPGAm(DMAE), PEG-PGAm(DEAE), and PEG-PGAm(DPAE). 


\section{Degradation Studies}

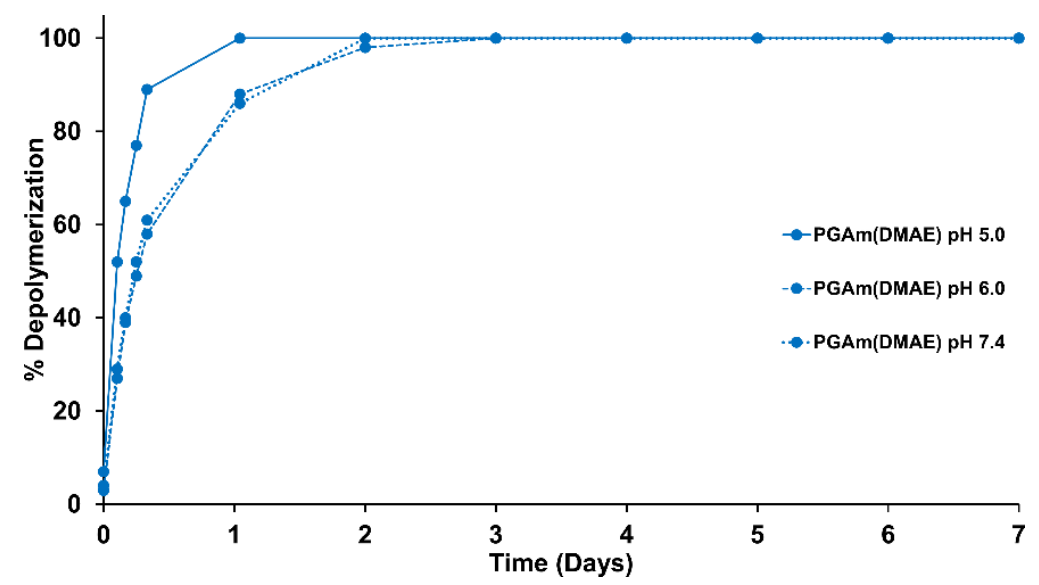

Figure S22. Depolymerization over time for PGAm(DMAE) at different $\mathrm{pH}$ levels, as measured by ${ }^{1} \mathrm{H}$ NMR spectroscopy. Deuterated potassium phosphate buffer (0.2 M; pH 7.4) or deuterated sodium citrate buffer $(0.2 \mathrm{M}$; pH 5.0, 6.0) was used as the solvent. The polymer was completely soluble at all $\mathrm{pH}$ levels tested.

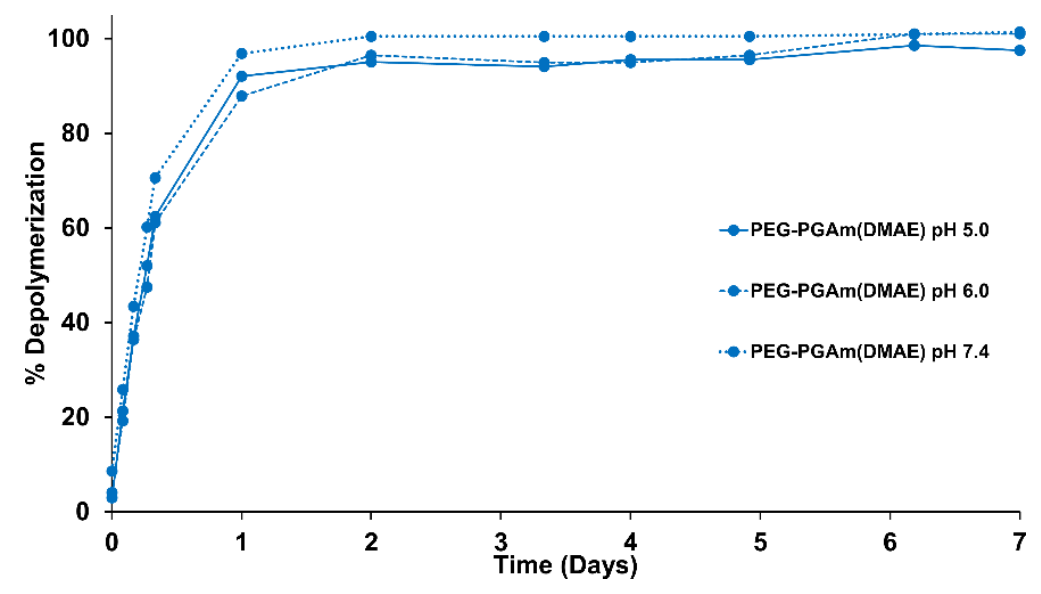

Figure S23. Depolymerization over time for PEG-PGAm(DMAE) at different $\mathrm{pH}$ levels, as measured by ${ }^{1} \mathrm{H}$ NMR spectroscopy. Deuterated potassium phosphate buffer $(0.2 \mathrm{M} ; \mathrm{pH} 7.4,8.0)$ or deuterated sodium citrate buffer $(0.2 \mathrm{M} ; \mathrm{pH} 5.0,6.0)$ was used as the solvent. 


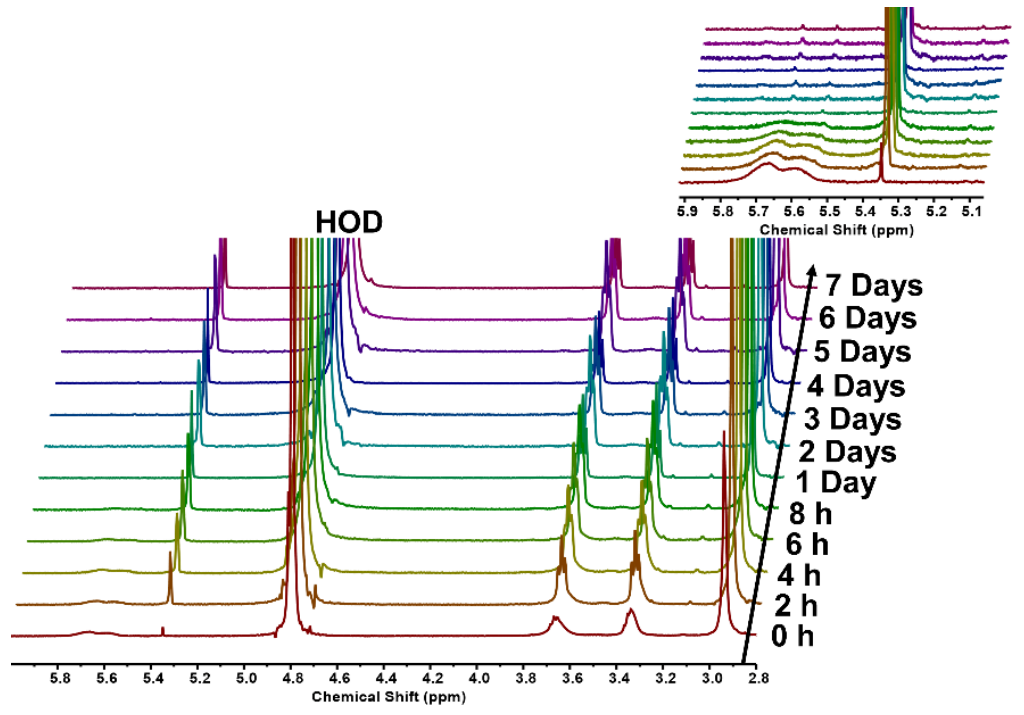

Figure S24. Depolymerization of PGAm(DMAE) over time in deuterated citrate buffer (0.2 M; pH 5.0) monitored by ${ }^{1} \mathrm{H}$ NMR spectroscopy $(400 \mathrm{~Hz})$. The peaks from the citrate buffer salts have been cropped out of the spectrum.

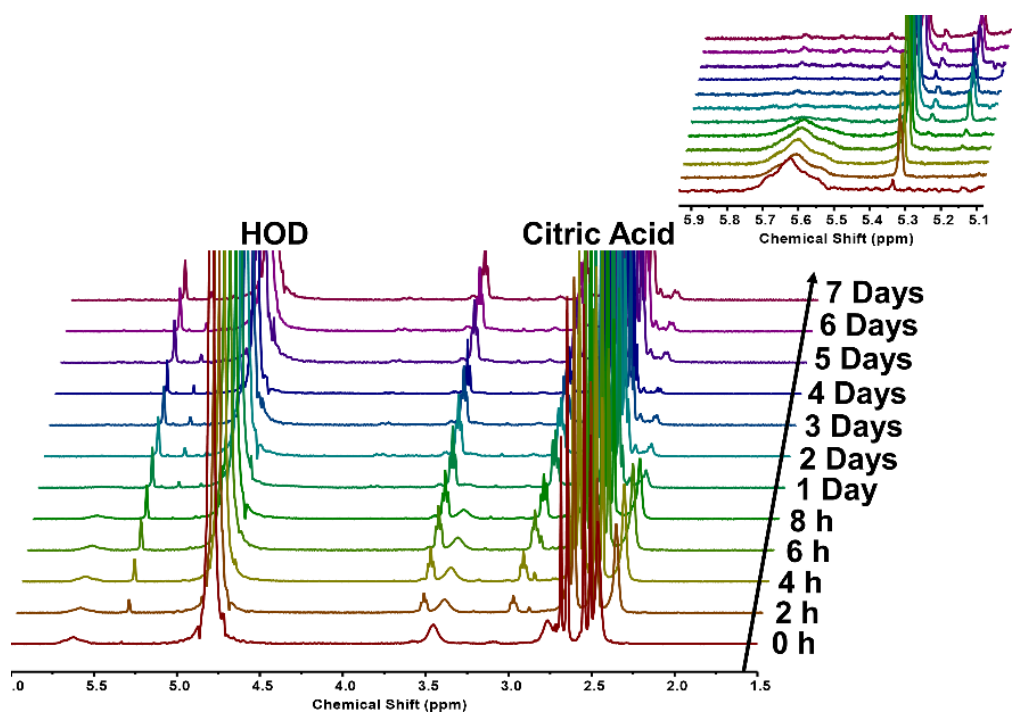

Figure S25. Depolymerization of PGAm(DMAE) over time in deuterated citrate buffer (0.2 M; pH 6.0) monitored by ${ }^{1} \mathrm{H}$ NMR spectroscopy $(400 \mathrm{~Hz})$. 


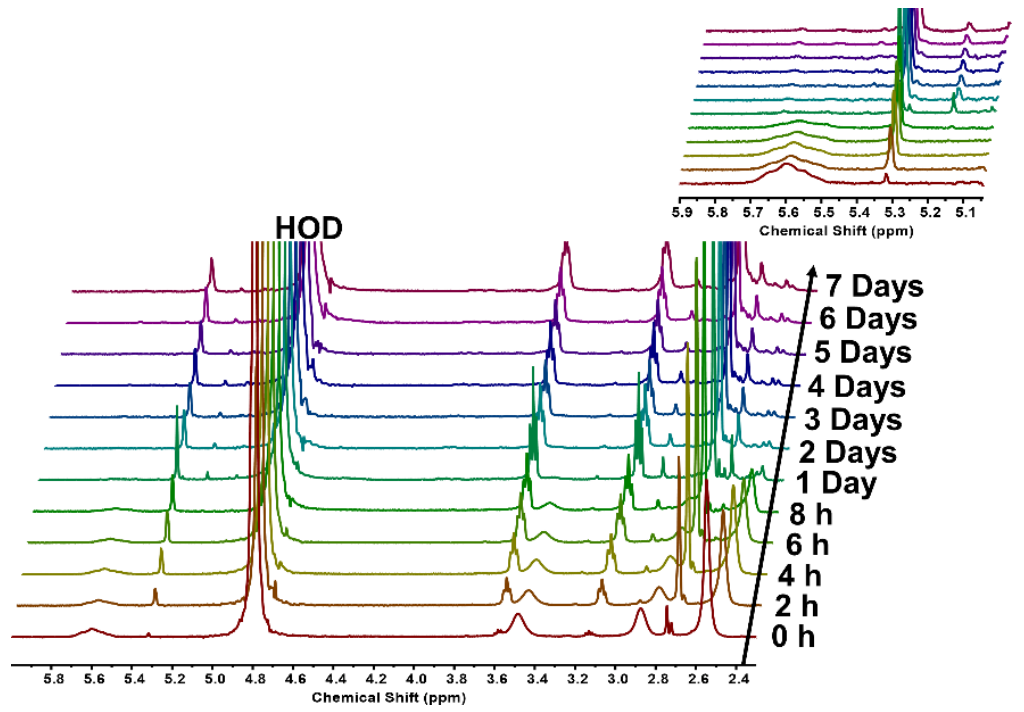

Figure S26. Depolymerization of PGAm(DMAE) over time in deuterated phosphate buffer $(0.2$ $\mathrm{M}$; pH 7.4) monitored by ${ }^{1} \mathrm{H}$ NMR spectroscopy $(400 \mathrm{~Hz})$.

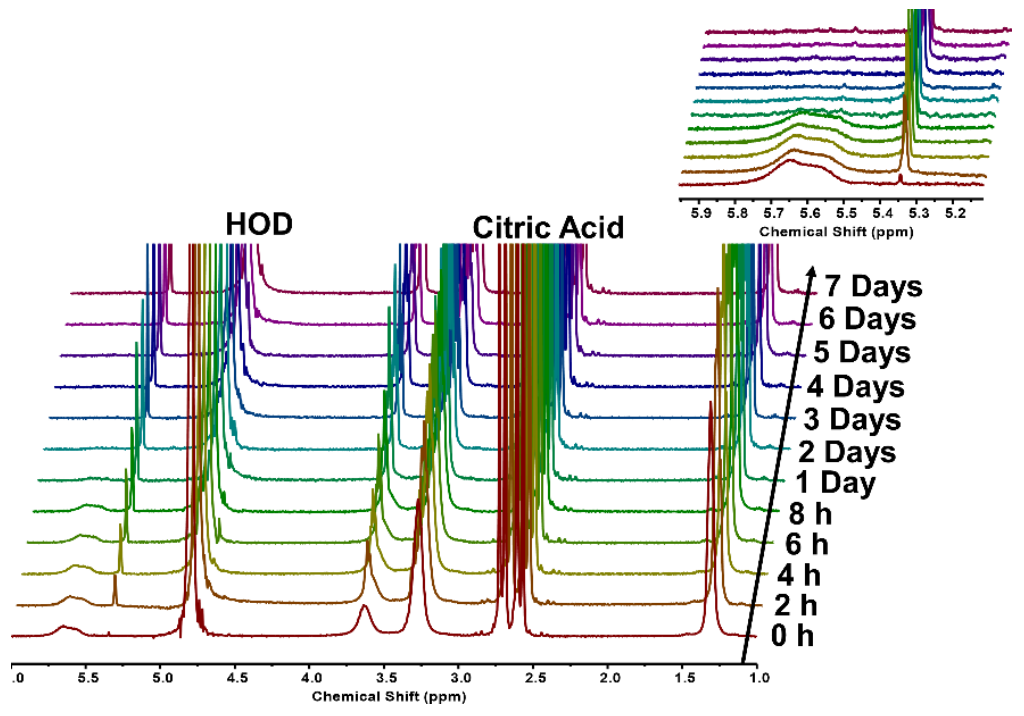

Figure S27. Depolymerization of PGAm(DEAE) over time in deuterated citrate buffer (0.2 M; pH 5.0) monitored by ${ }^{1} \mathrm{H}$ NMR spectroscopy (400 Hz). 


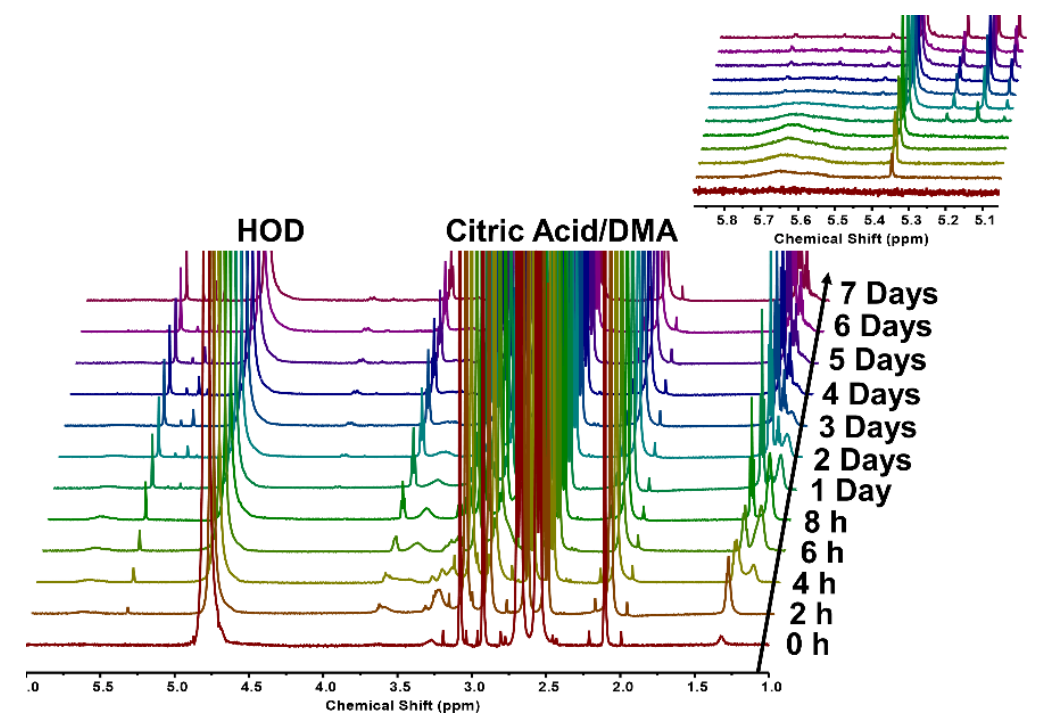

Figure S28. Depolymerization of PGAm(DEAE) over time in deuterated citrate buffer (0.2 M; pH 6.0) monitored by ${ }^{1} \mathrm{H}$ NMR spectroscopy (600 Hz). DMA was added as an internal standard.

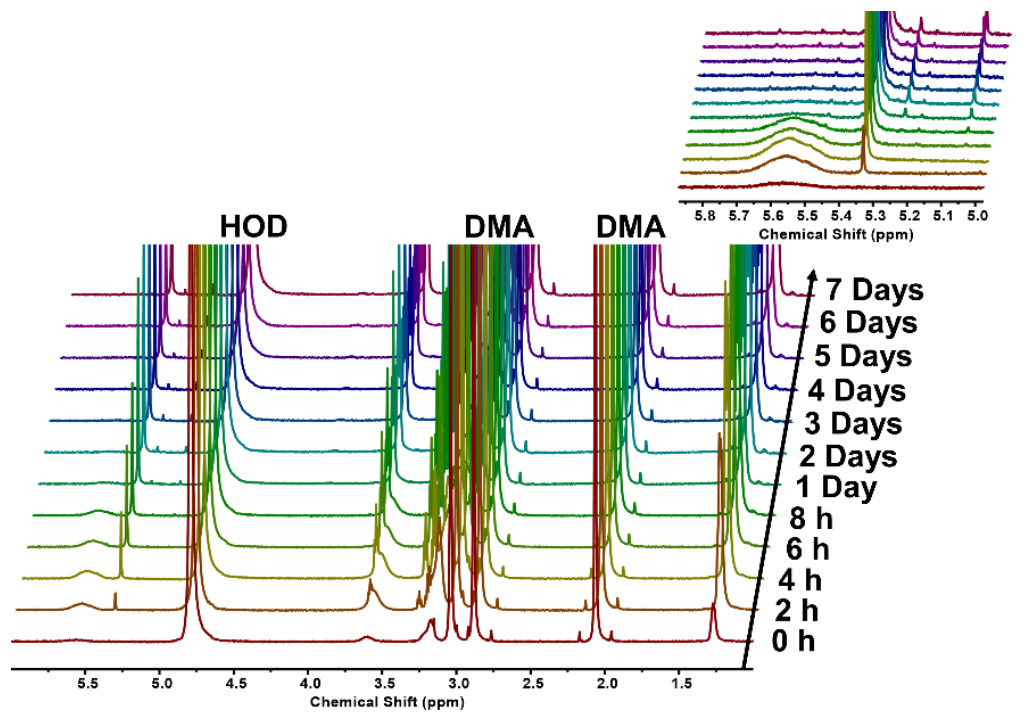

Figure S29. Depolymerization of PGAm(DEAE) over time in deuterated phosphate buffer $(0.2$ M; pH 7.4) monitored by ${ }^{1} \mathrm{H}$ NMR spectroscopy (600 Hz). DMA was added as an internal standard. 


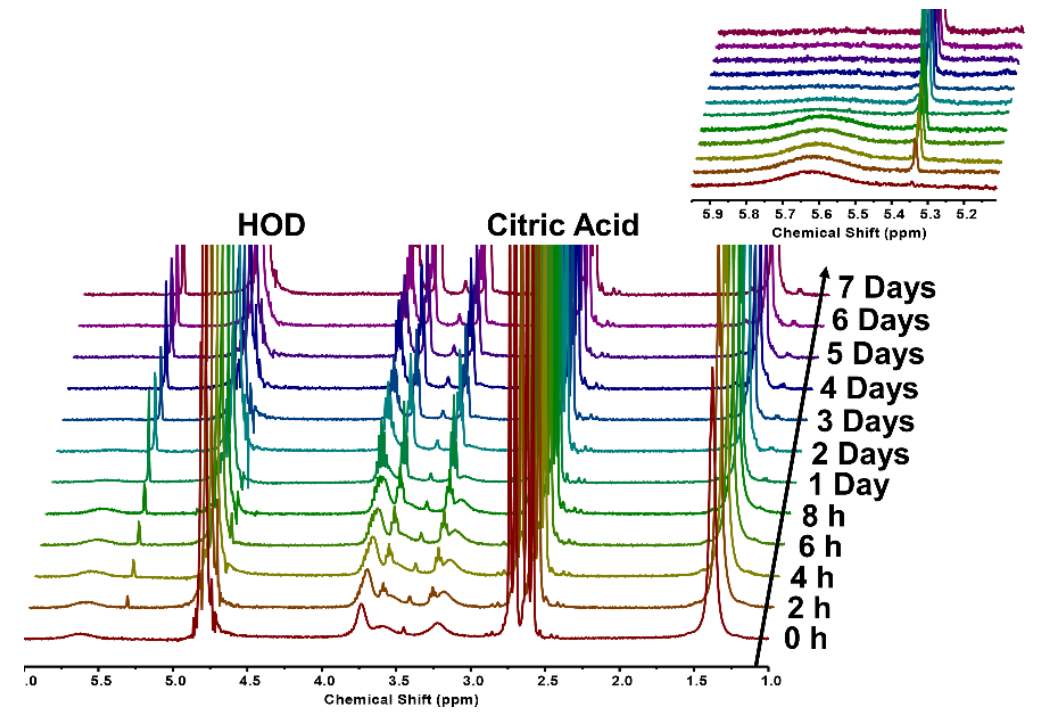

Figure S30. Depolymerization of PGAm(DPAE) over time in deuterated citrate buffer (0.2 M; pH 5.0) monitored by ${ }^{1} \mathrm{H}$ NMR spectroscopy (400 Hz).

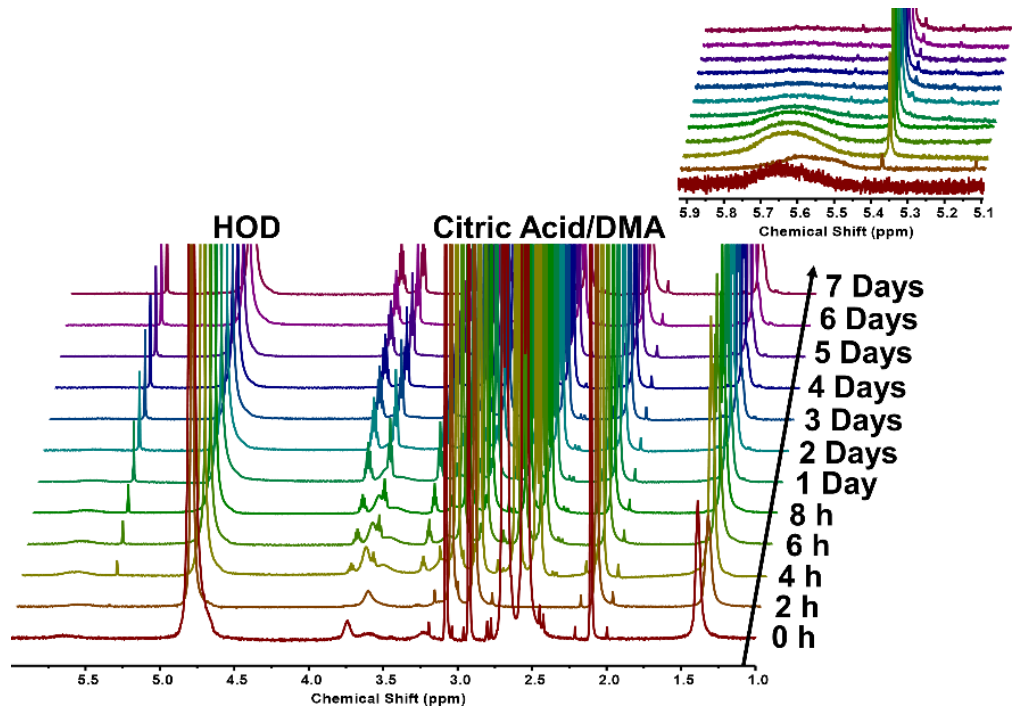

Figure S31. Depolymerization of PGAm(DPAE) over time in deuterated citrate buffer (0.2 M; pH 6.0) monitored by ${ }^{1} \mathrm{H}$ NMR spectroscopy (600 Hz). DMA was added as an internal standard. 


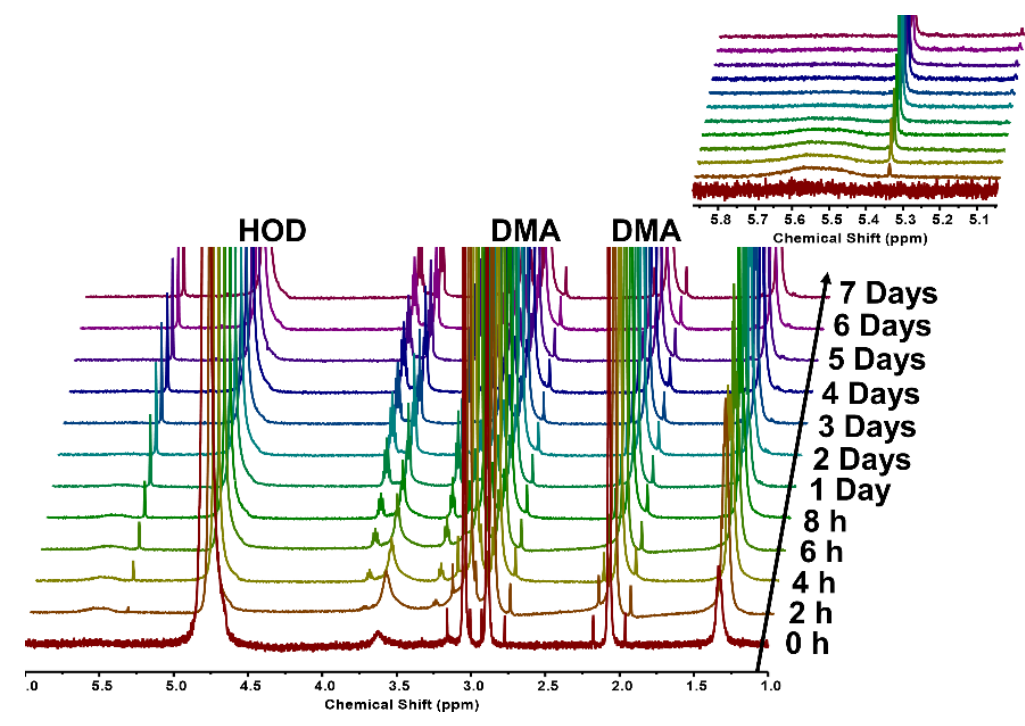

Figure S32. Depolymerization of PGAm(DPAE) over time in deuterated phosphate buffer $(0.2$ M; pH 7.4) monitored by ${ }^{1} \mathrm{H}$ NMR spectroscopy $(600 \mathrm{~Hz})$. DMA was added as an internal standard.

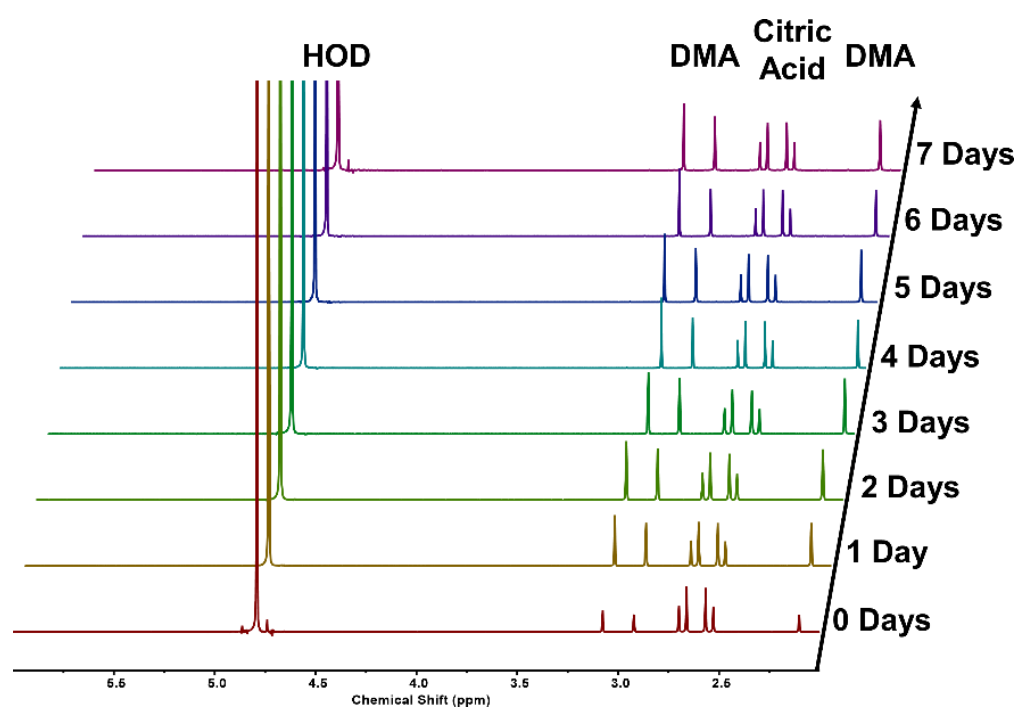

Figure S33. Depolymerization of PEtG-1 over time in deuterated citrate buffer (0.2 M; pH 5.0) monitored by ${ }^{1} \mathrm{H}$ NMR spectroscopy $(400 \mathrm{~Hz})$. DMA was added as an internal standard. 


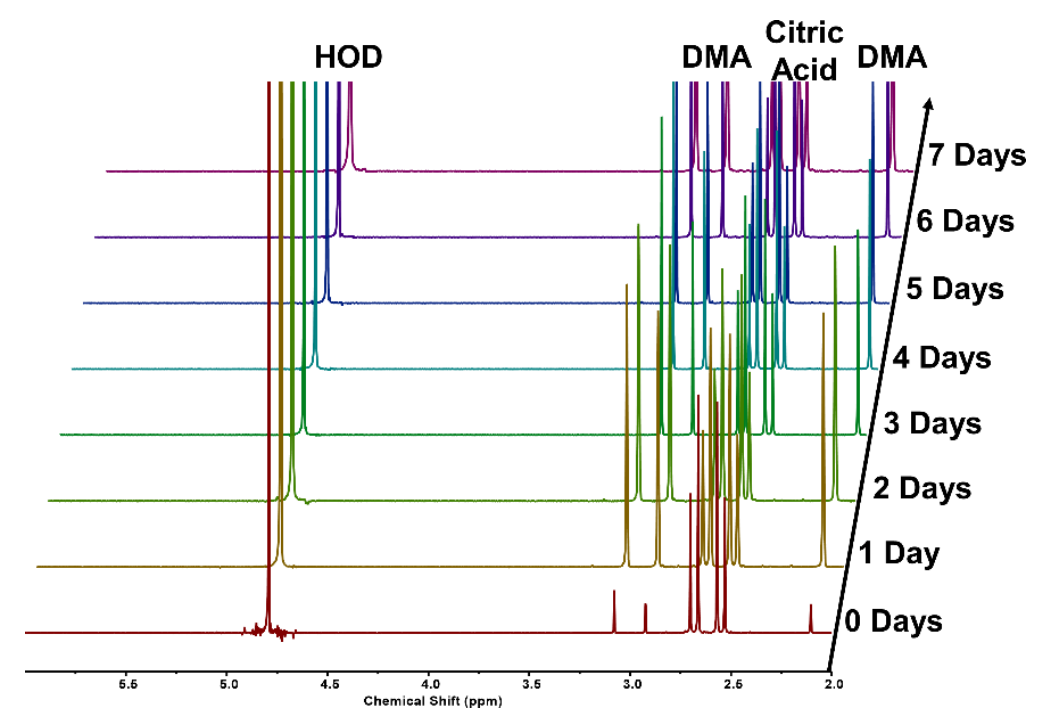

Figure S34. Depolymerization of PEtG-1 over time in deuterated citrate buffer (0.2 M; pH 5.0) monitored by ${ }^{1} \mathrm{H}$ NMR spectroscopy $(400 \mathrm{~Hz})$. DMA was added as an internal standard.

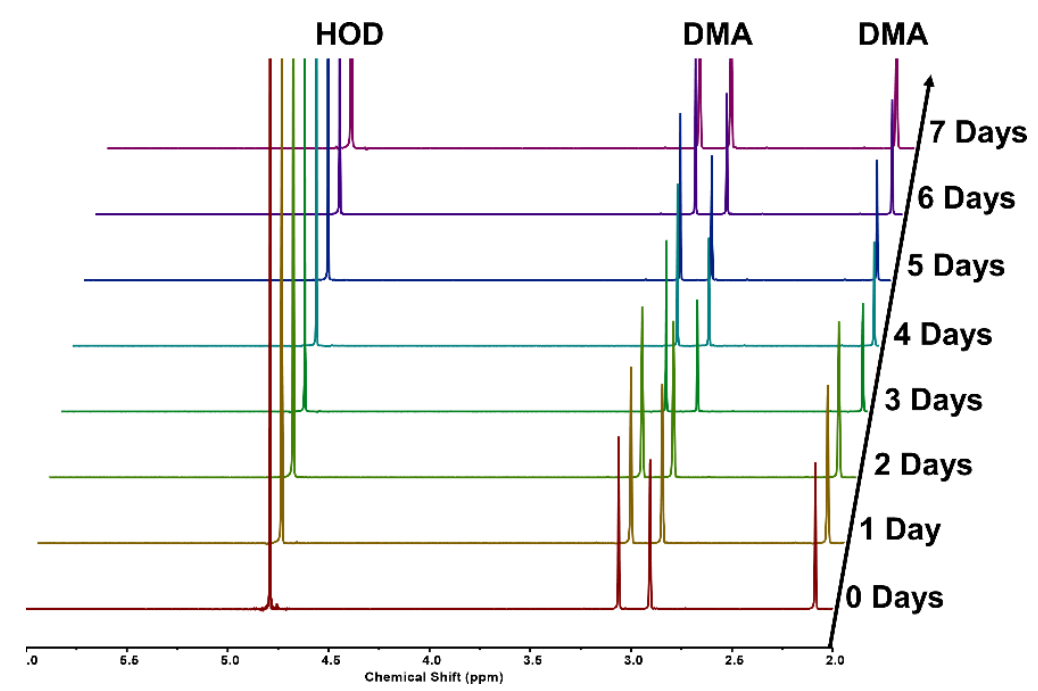

Figure S35. Depolymerization of PEtG-1 over time in deuterated phosphate buffer (0.2 M; $\mathrm{pH}$ 7.4) monitored by ${ }^{1} \mathrm{H}$ NMR spectroscopy (400 Hz). DMA was added as an internal standard. 


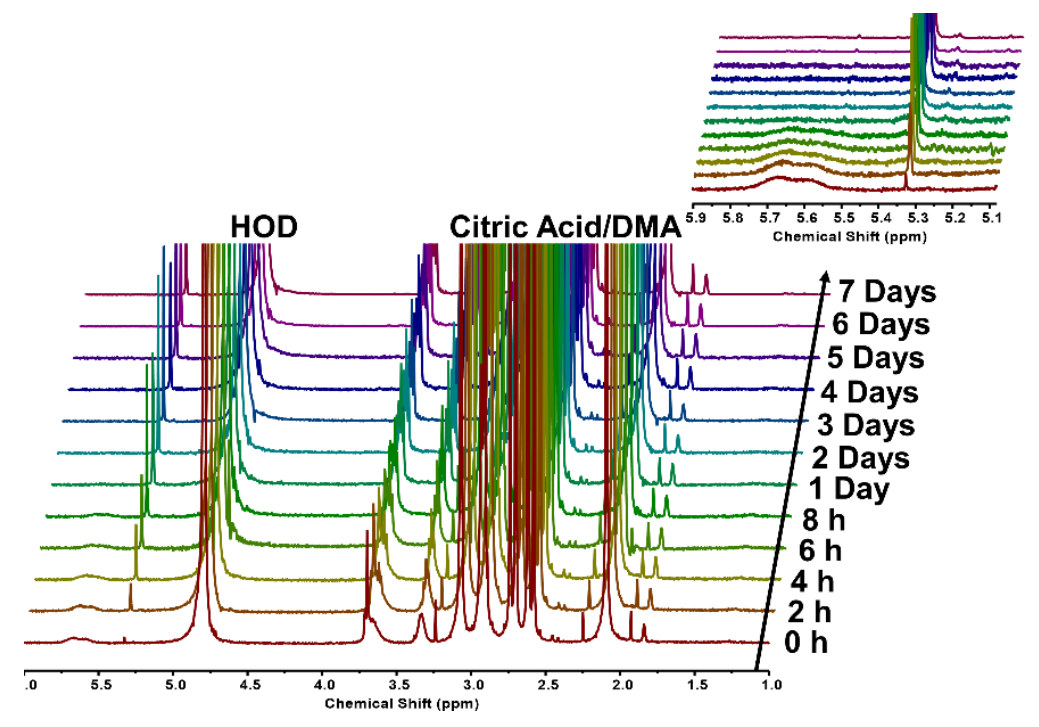

Figure S36. Depolymerization of PEG-PGAm(DMAE) over time in deuterated citrate buffer (0.2 M; pH 5.0) monitored by ${ }^{1} \mathrm{H}$ NMR spectroscopy (400 Hz). DMA was added as an internal standard.

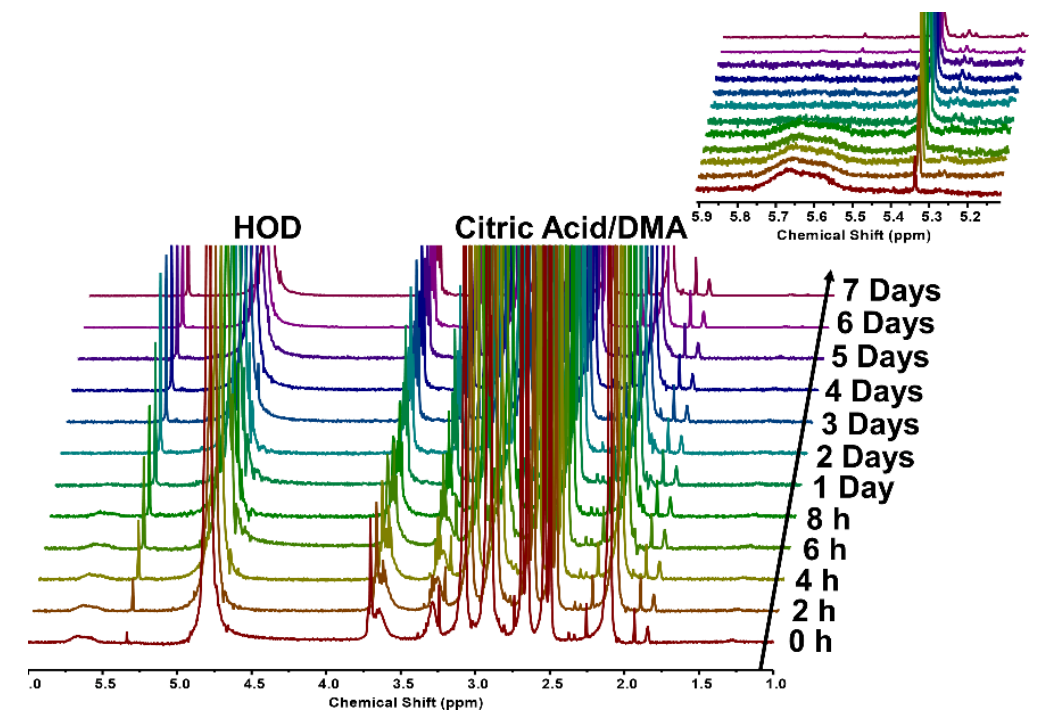

Figure S37. Depolymerization of PEG-PGAm(DMAE) over time in deuterated citrate buffer (0.2 M; pH 6.0) monitored by ${ }^{1} \mathrm{H}$ NMR spectroscopy (400 Hz). DMA was added as an internal standard. 


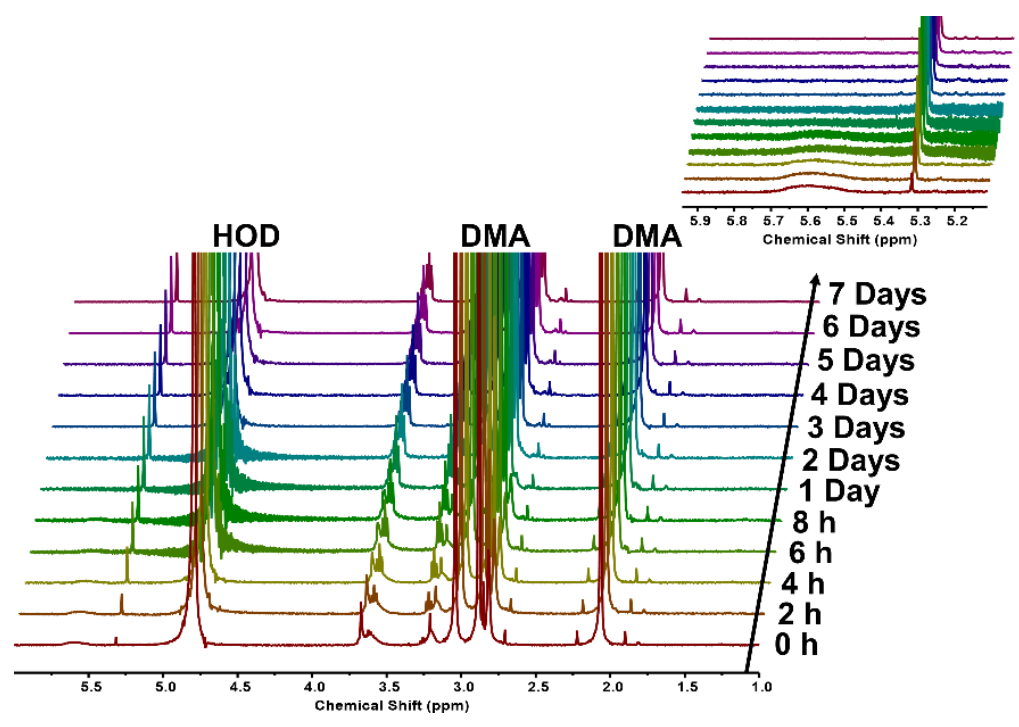

Figure S38. Depolymerization of PEG-PGAm(DMAE) over time in deuterated phosphate buffer (0.2 M; pH 7.4) monitored by ${ }^{1} \mathrm{H}$ NMR spectroscopy (400 Hz). DMA was added as an internal standard.

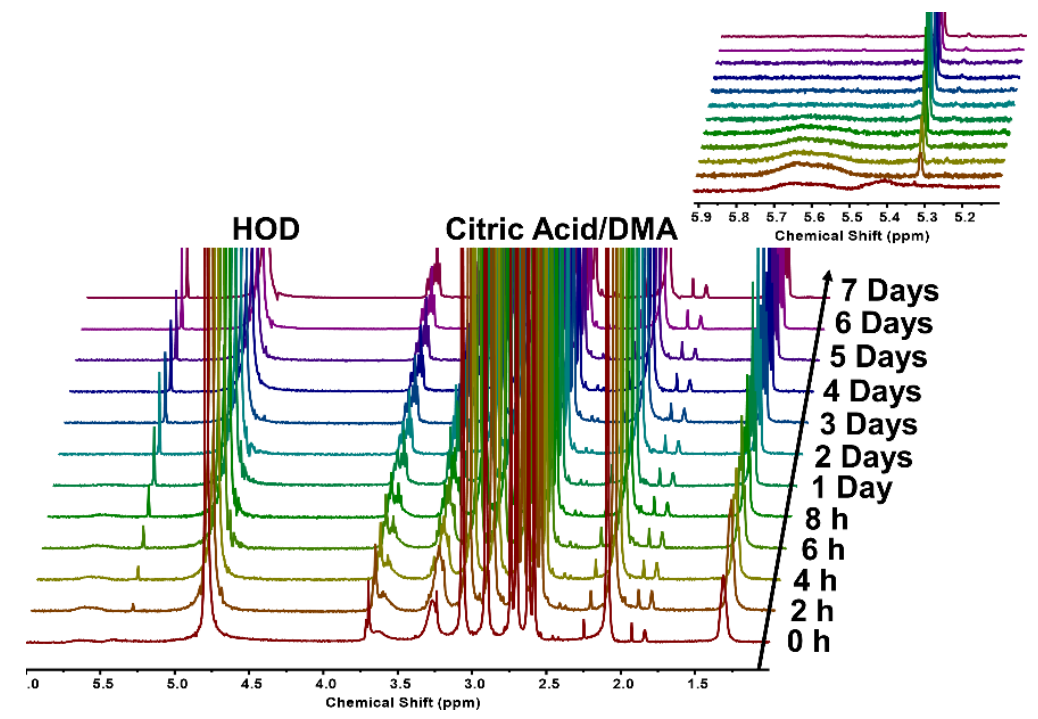

Figure S39. Depolymerization of PEG-PGAm(DEAE) over time in deuterated citrate buffer $(0.2$ M; pH 5.0) monitored by ${ }^{1} \mathrm{H}$ NMR spectroscopy (400 Hz). DMA was added as an internal standard. 


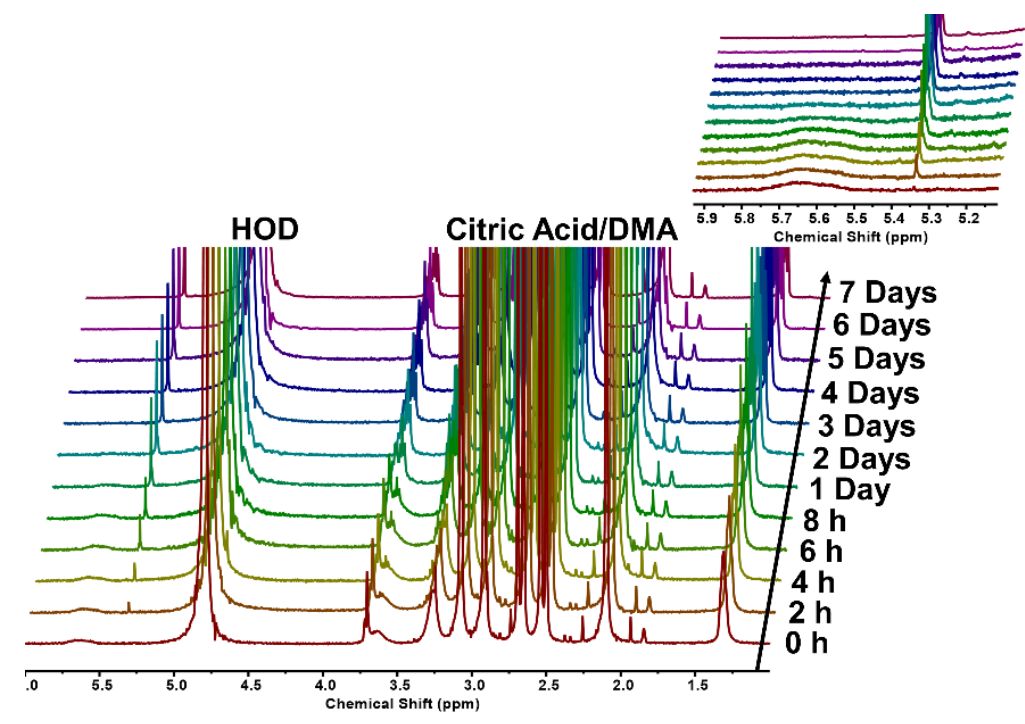

Figure S40. Depolymerization of PEG-PGAm(DEAE) over time in deuterated citrate buffer $(0.2$ M; pH 6.0) monitored by ${ }^{1} \mathrm{H}$ NMR spectroscopy (400 Hz). DMA was added as an internal standard.

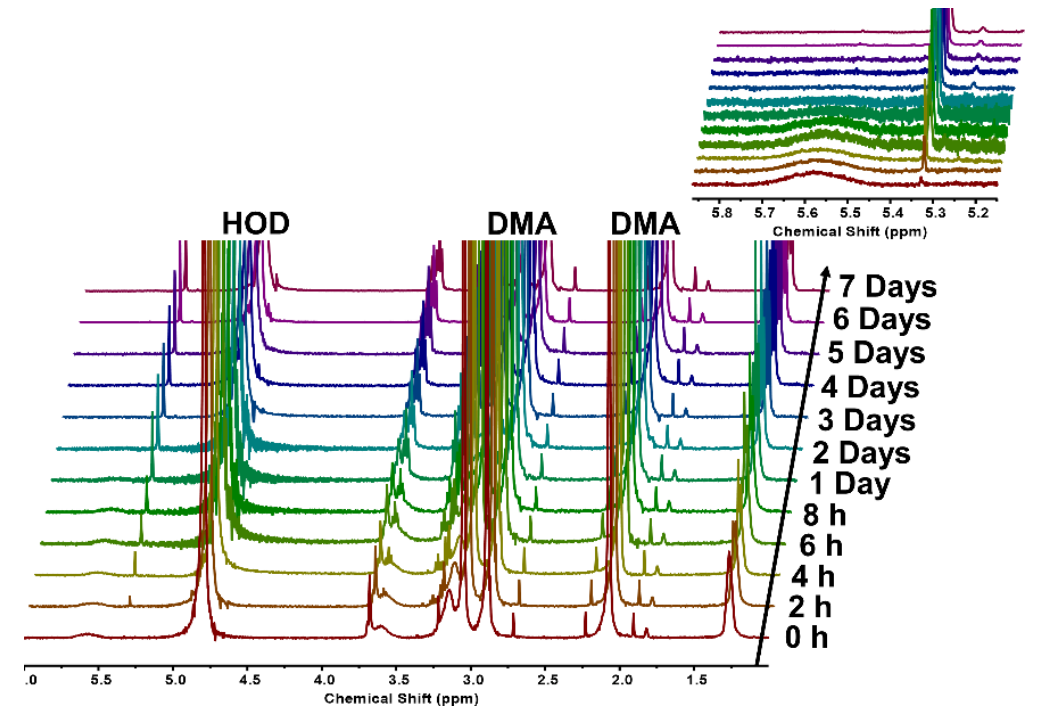

Figure S41. Depolymerization of PEG-PGAm(DEAE) over time in deuterated phosphate buffer (0.2 M; pH 7.4) monitored by ${ }^{1} \mathrm{H}$ NMR spectroscopy (400 Hz). DMA was added as an internal standard. 


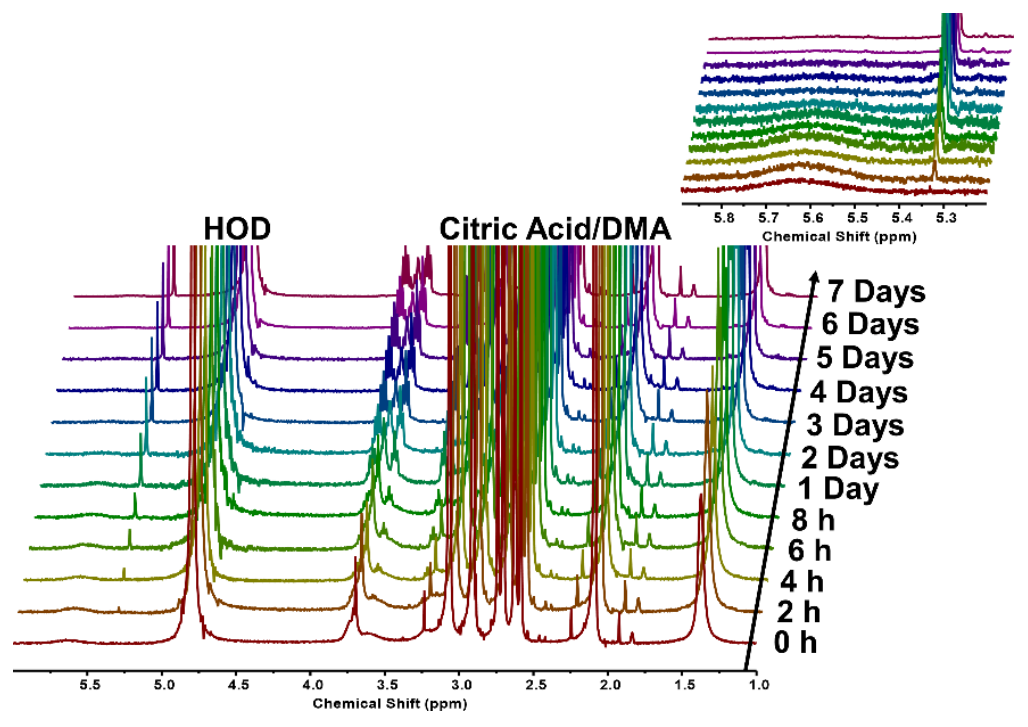

Figure S42. Depolymerization of PEG-PGAm(DPAE) over time in deuterated citrate buffer (0.2 M; pH 5.0) monitored by ${ }^{1} \mathrm{H}$ NMR spectroscopy (400 Hz). DMA was added as an internal standard.

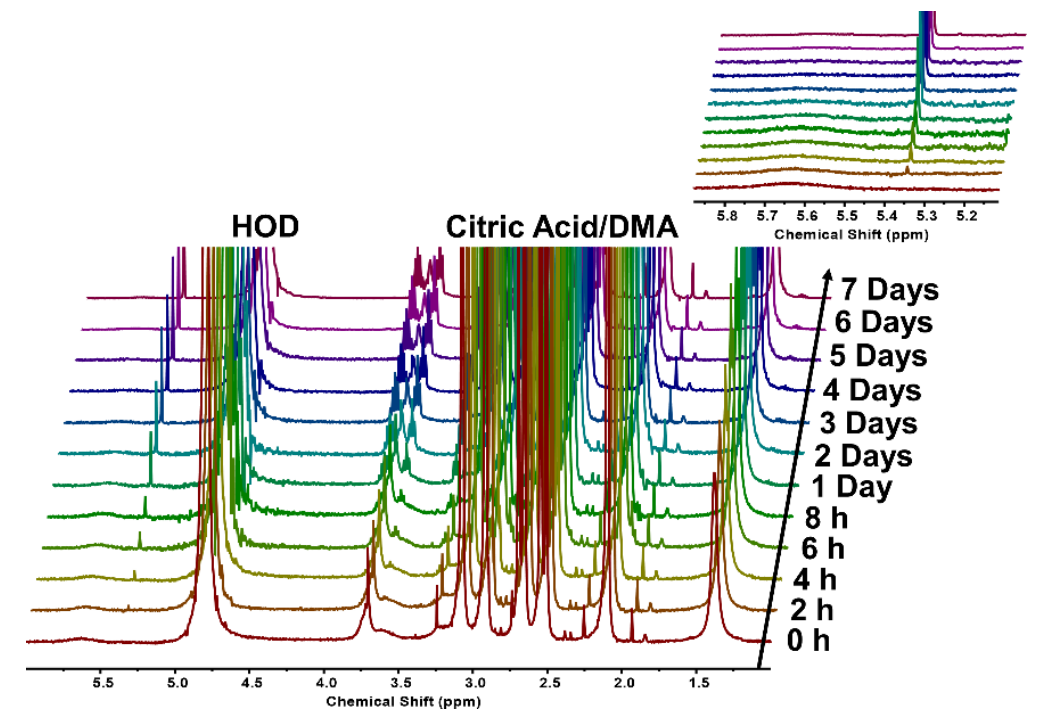

Figure S43. Depolymerization of PEG-PGAm(DPAE) over time in deuterated citrate buffer $(0.2$ M; pH 6.0) monitored by ${ }^{1} \mathrm{H}$ NMR spectroscopy (400 Hz). DMA was added as an internal standard. 


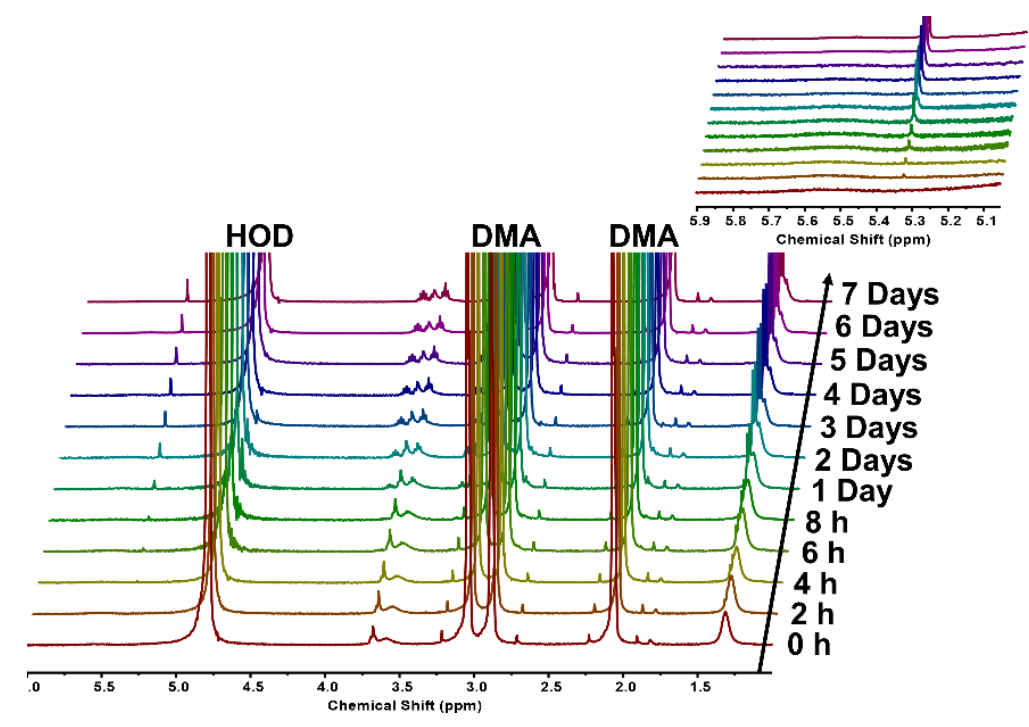

Figure S44. Depolymerization of PEG-PGAm(DPAE) over time in deuterated phosphate buffer (0.2 M; pH 7.4) monitored by ${ }^{1} \mathrm{H}$ NMR spectroscopy $(400 \mathrm{~Hz})$. DMA was added as an internal standard.

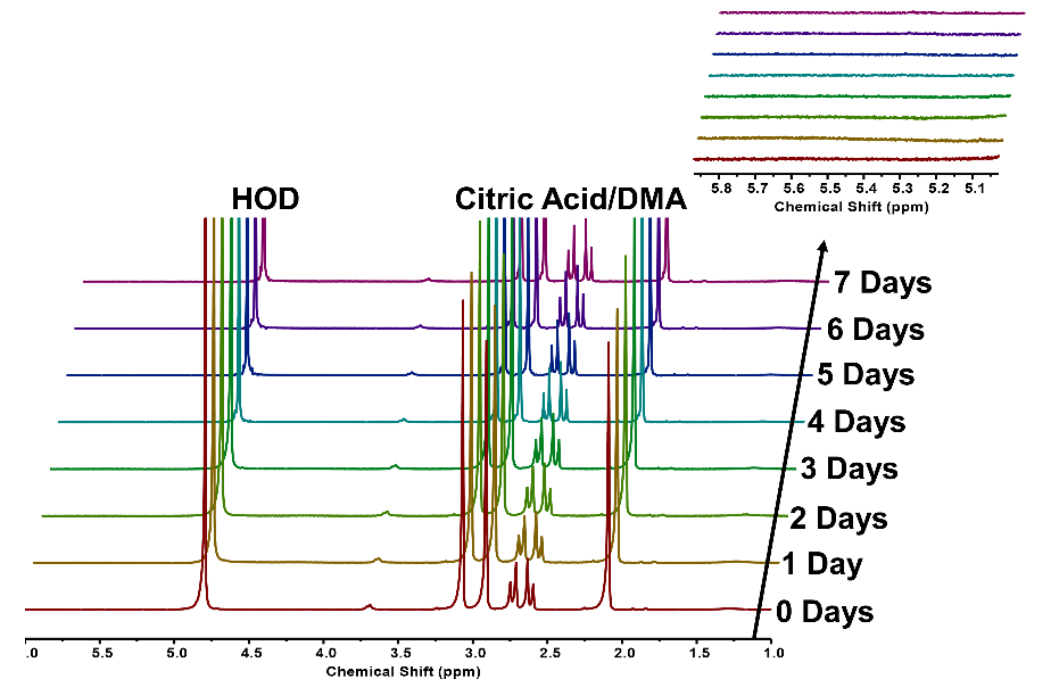

Figure S45. Depolymerization of PEG-PEtG over time in deuterated citrate buffer $(0.2 \mathrm{M}$; $\mathrm{pH}$ 5.0) monitored by ${ }^{1} \mathrm{H}$ NMR spectroscopy $(400 \mathrm{~Hz})$. DMA was added as an internal standard. 


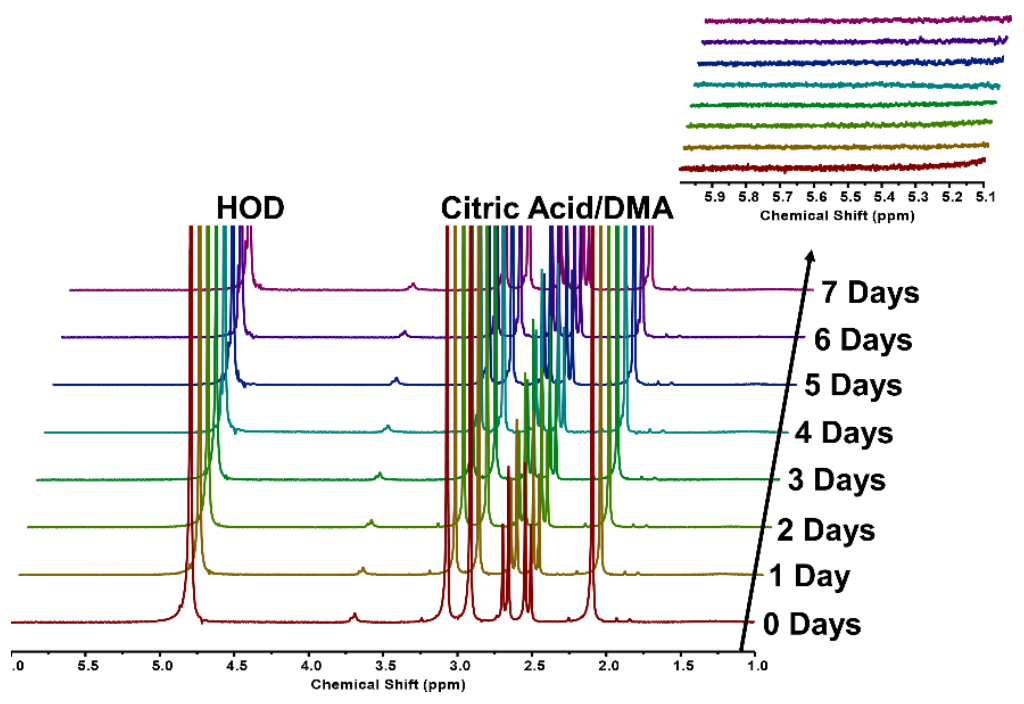

Figure S46. Depolymerization of PEG-PEtG over time in deuterated citrate buffer $(0.2 \mathrm{M} ; \mathrm{pH}$ 6.0) monitored by ${ }^{1} \mathrm{H}$ NMR spectroscopy (400 Hz). DMA was added as an internal standard.

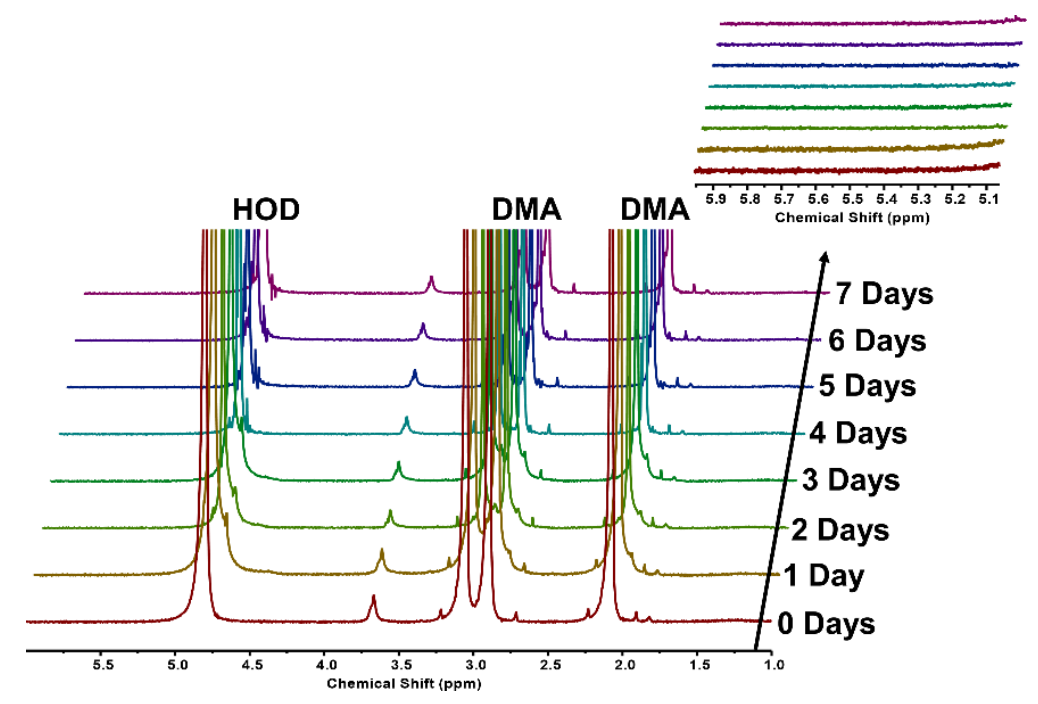

Figure S47. Depolymerization of PEG-PEtG over time in deuterated phosphate buffer (0.2 M; pH 7.4) monitored by ${ }^{1} \mathrm{H}$ NMR spectroscopy (400 Hz). DMA was added as an internal standard. 


\section{Dynamic Light Scattering Studies}

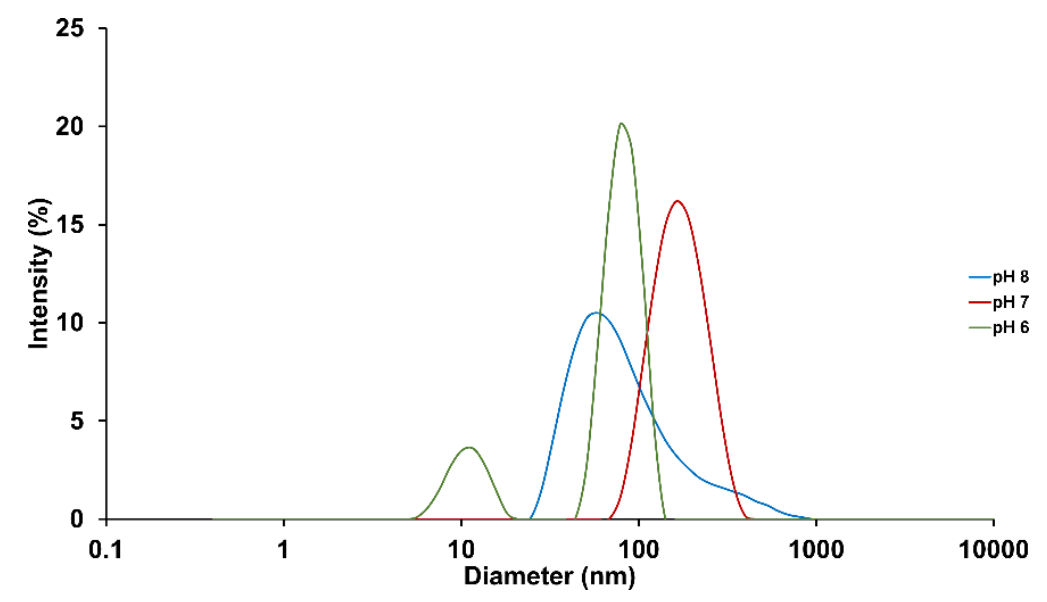

Figure S48. Intensity distributions for PEG-PGAm(DPAE) assemblies at different $\mathrm{pH}$ levels (at $\left.25^{\circ} \mathrm{C}\right)$.

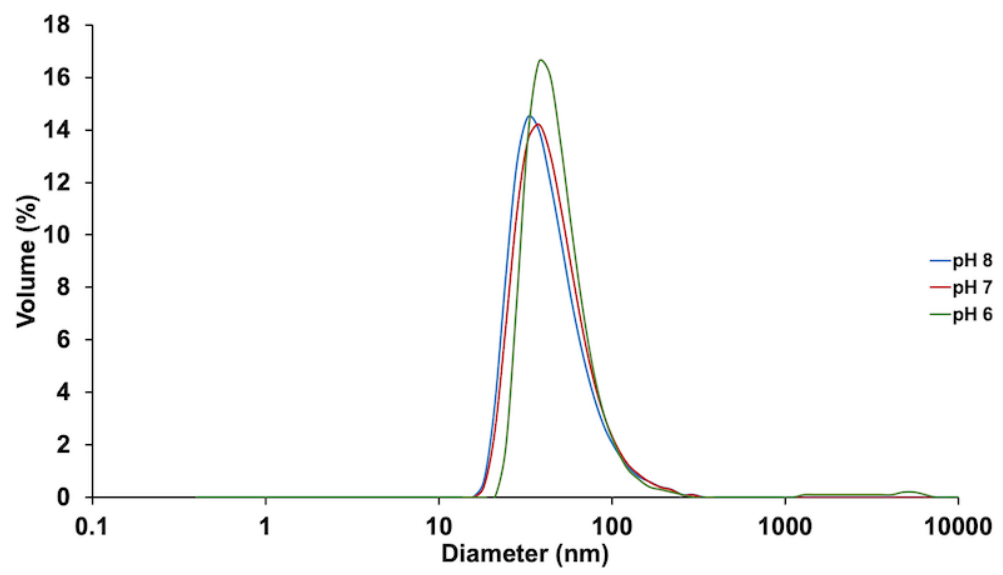

Figure S49. Volume distributions of PEG-PEtG assemblies at different $\mathrm{pH}$ levels $\left(25^{\circ} \mathrm{C}\right)$. 


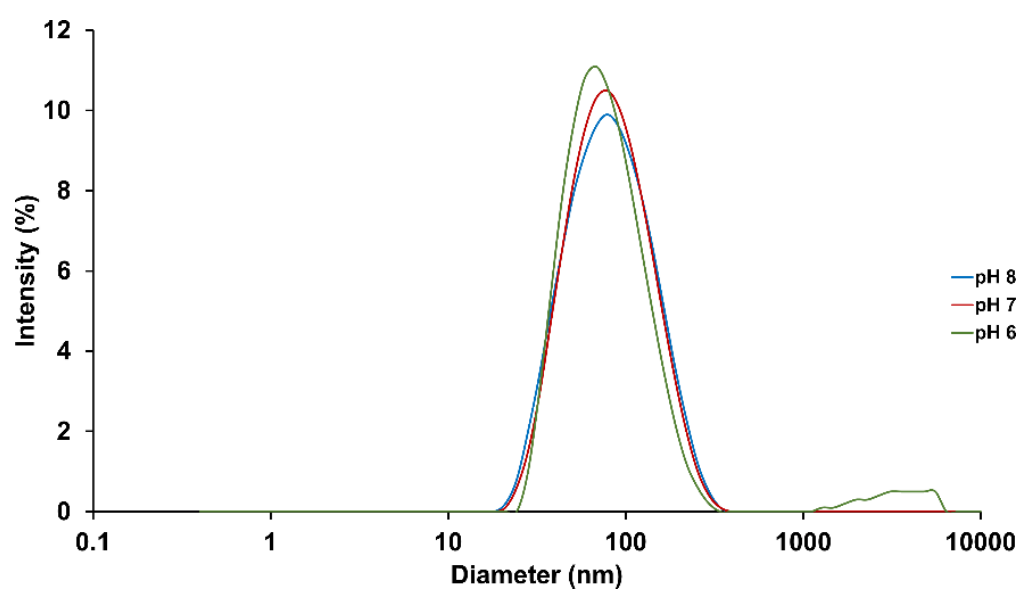

Figure S50. Intensity distributions for PEG-PEtG assemblies at different $\mathrm{pH}$ levels (at $25{ }^{\circ} \mathrm{C}$ ). 


\section{Fluorescence Studies}
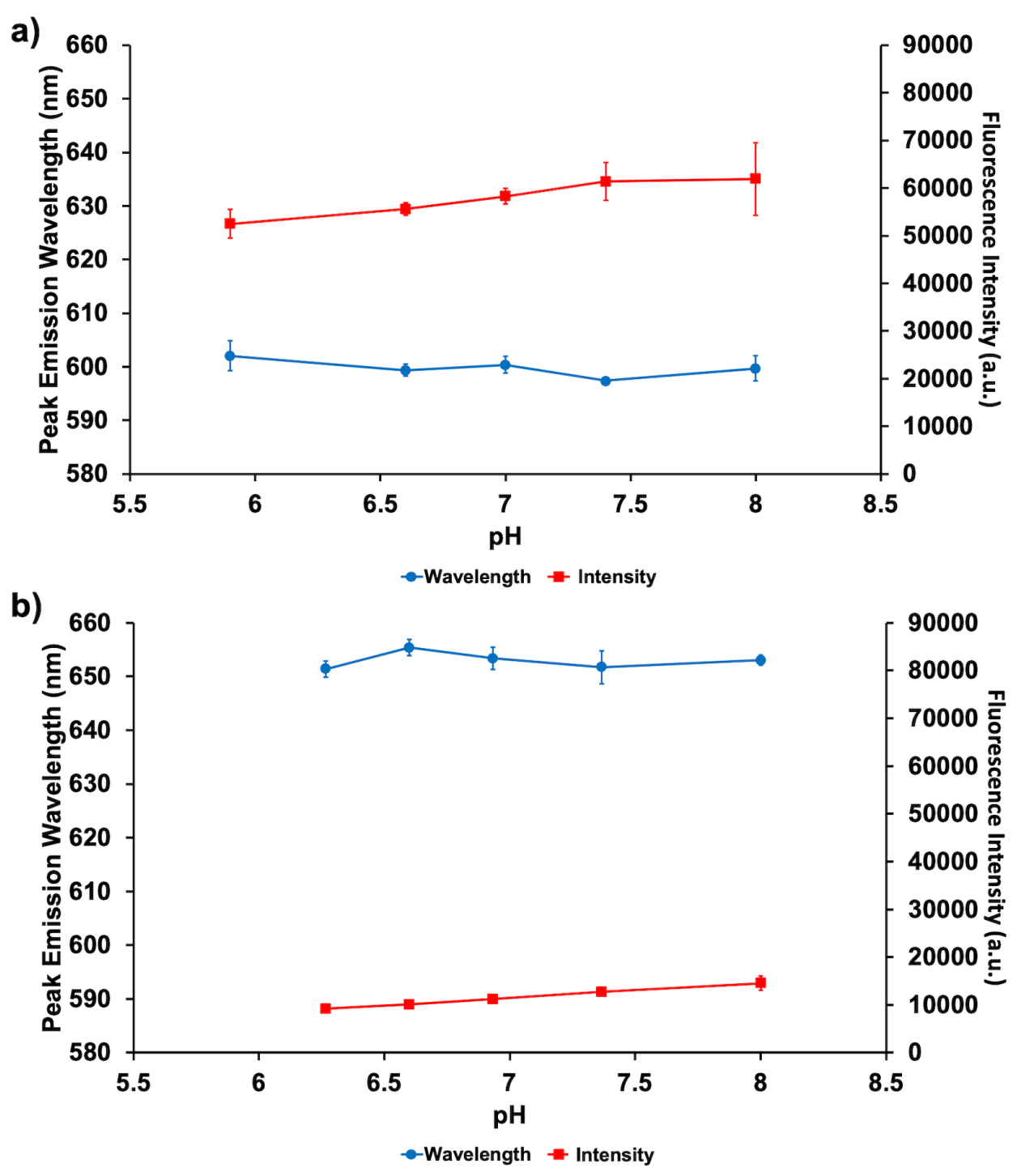

Figure S51. Changes in the fluorescence intensity and peak emission wavelength of Nile red between $\mathrm{pH} 8$ and pH 6 (0.2 M phosphate solution) a) when encapsulated into PEG-PEtG nanoassemblies; b) when in solution without any polymer. Error bars represent the standard deviation of triplicate samples. 


\section{Kinetic analysis}
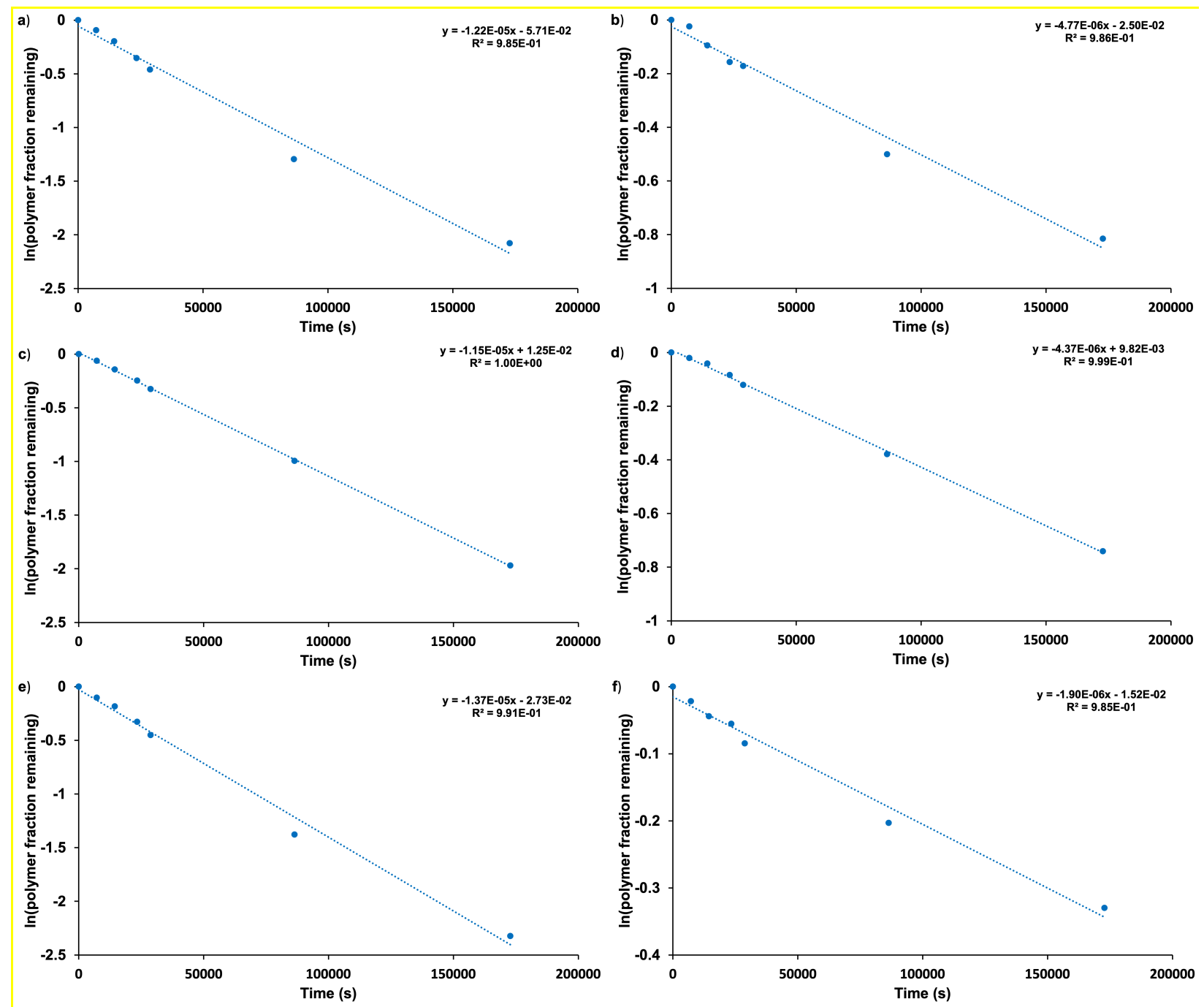

Figure S52. Pseudo-first-order kinetic plots for the depolymerization of PEG-PGAm(DEAE) (a, c, e) and PEG-PGAm(DPAE) (b, d, f) at pH 5 (a, b), pH 6 (c, d), and pH 7.4 (e, f). 
Table S1. Pseudo-first-order rate constants for the depolymerization of PEG-PGAm(DEAE) and PEG-PGAm(DPAE) at different $\mathrm{pH}$ levels.

\begin{tabular}{ccc}
\hline $\mathbf{p H}$ & $\begin{array}{c}\text { PEG-PGAm(DEAE) Rate } \\
\text { Constant }\left(\mathbf{s}^{-1}\right)\end{array}$ & $\begin{array}{c}\text { PEG-PGAm(DPAE) Rate } \\
\text { Constant }\left(\mathbf{s}^{-1}\right)\end{array}$ \\
\hline 5.0 & $1.22 \times 10^{-5}$ & $4.77 \times 10^{-6}$ \\
6.0 & $1.15 \times 10^{-5}$ & $4.37 \times 10^{-6}$ \\
7.4 & $1.37 \times 10^{-5}$ & $1.90 \times 10^{-6}$ \\
\hline
\end{tabular}

\section{References}

1. Rabiee Kenaree, A.; Gillies, E. R. Controlled Polymerization of Ethyl Glyoxylate Using Alkyllithium and Alkoxide Initiators. Macromolecules 2018, 51, 5501-5510. 